\title{
Current molecular and clinical insights into uveal melanoma (Review)
}

\author{
MATTEO FALLICO $^{1 *}$, GIUSEPPINA RACITI ${ }^{2 *}$, ANTONIO LONGO $^{1}$, MICHELE REIBALDI $^{3}$, \\ VINCENZA BONFIGLIO ${ }^{4}$, ANDREA RUSSO $^{1}$, ROSARIO CALTABIANO $^{5}$, \\ GIUSEPPE GATTUSO $^{6}$, LUCA FALZONE ${ }^{7}$ and TERESIO AVITABILE ${ }^{1}$
}

${ }^{1}$ Department of Ophthalmology, University of Catania, I-95123 Catania; ${ }^{2}$ Department of Drug Sciences, Section of Biochemistry, University of Catania, I-95125 Catania; ${ }^{3}$ Department of Surgical Sciences,

Eye Clinic Section, University of Turin, I-10122 Turin; ${ }^{4}$ Department of Experimental Biomedicine and Clinical Neuroscience, Ophthalmology Section, University of Palermo, I-90127 Palermo; ${ }^{5}$ Department 'G.F. Ingrassia', Section of Anatomic Pathology, and ${ }^{6}$ Department of Biomedical and Biotechnological Sciences, University of Catania, I-95123 Catania; ${ }^{7}$ Epidemiology Unit, IRCCS Istituto Nazionale Tumori ‘Fondazione G. Pascale', I-80131 Naples, Italy

Received October 27, 2020; Accepted November 30, 2020

DOI: $10.3892 /$ ijo.2021.5190

\begin{abstract}
Uveal melanoma (UM) represents the most prominent primary eye cancer in adults. With an incidence of approximately 5 cases per million individuals annually in the United States, UM could be considered a relatively rare cancer. The $90-95 \%$ of UM cases arise from the choroid. Diagnosis is based mainly on a clinical examination and ancillary tests, with ocular ultrasonography being of greatest value. Differential diagnosis can prove challenging in the case of indeterminate choroidal lesions and, sometimes, monitoring for documented growth may be the proper approach. Fine needle aspiration biopsy tends to be performed with a prognostic purpose, often in combination with radiotherapy. Gene expression profiling has allowed for the grading of UMs into two classes, which feature different metastatic risks. Patients with UM require a specialized multidisciplinary management. Primary tumor treatment can be either enucleation or globe preserving. Usually, enucleation is reserved for larger tumors, while radiotherapy is preferred for small/medium melanomas. The prognosis is unfavorable due to the high mortality rate and high tendency to metastasize. Following the development of metastatic disease, the mortality rate increases to $80 \%$ within one year, due to both the absence of an effective treatment and the
\end{abstract}

Correspondence to: Dr Luca Falzone, Epidemiology Unit, IRCCS Istituto Nazionale Tumori 'Fondazione G. Pascale', Via Mariano Semmola 53, I-80131 Naples, Italy

E-mail: 1.falzone@istitutotumori.na.it

${ }^{*}$ Contributed equally

Key words: uveal melanoma, staging, treatment, diagnosis, prognosis, biomarkers, epigenetics aggressiveness of the condition. Novel molecular studies have allowed for a better understanding of the genetic and epigenetic mechanisms involved in UM biological activity, which differs compared to skin melanomas. The most commonly mutated genes are GNAQ, GNA11 and BAP1. Research in this field could help to identify effective diagnostic and prognostic biomarkers, as well as novel therapeutic targets.

\section{Contents}

1. Introduction

2. Epidemiology

3. Risk factors

4. Clinical characteristics

5. Diagnosis

6. Staging

7. Prognosis

8. Primary tumor treatment

9. Surveillance and metastatic disease treatment

10. Genetic and epigenetic features in uveal melanoma

11. Conclusions

\section{Introduction}

Uveal melanoma (UM) represents the most prominent primary eye cancer in adults. Although it could be considered a relatively rare tumor, UM remains a disease of primary interest due to its high mortality rate.

Notable efforts have been made to improve the management of this malignancy. The introduction of globe-sparing treatments was the most significant breakthrough of the last century in this field. However, the overall survival of affected patients has remained unaltered, and there is still no effective treatment for metastatic disease. 
Recently, increasing attention has focused on the molecular mechanisms involved in UM carcinogenesis and progression, which could allow for the identification of valuable diagnostic and prognostic biomarkers, as well as novel therapeutic targets.

Herein, the available evidence on epidemiological, clinical and molecular aspects of UM is discussed and reviewed, with an aim of providing an updated and comprehensive tool, which may be useful for both clinicians and researchers.

\section{Epidemiology}

UM represents $3-5 \%$ of all melanomas $(1,2)$. The largest proportion of cases of UM, approximately $85-90 \%$, arises from the choroid, while the $5-8 \%$ arises from the ciliary body and the $3-5 \%$ from the iris $(2,3)$. The incidence of UM in the United States, between 1973 and 2008, amounted to 5.1 cases per million annually (4). In Europe, a cancer registry-based study demonstrated a north-to-south decreasing gradient in the incidence of UM, with an incidence of $>8$ cases per million in Norway and Denmark compared with approximately 2 cases per million in Spain and Southern Italy (5). Likewise, in Africa and Asia, the incidence is low, amounting to $0.2-0.3$ cases per million per year (6). This latitude-related decreasing trend in the incidence of UM has been associated with the protective role of ocular pigmentation, which is higher in southern countries compared to northern ones (5). Similarly, dark skin pigmentation may play a role in protecting populations of African origin: The ratio of UM among populations of African origin vs. Caucasian populations ranges from 1:15 to 1:50 (7-9). A population-based study investigated the relative risk of UM in several racial cohorts, revealing a 5-fold higher risk among Hispanic populations and 19-fold higher risk among non-Hispanic Caucasian populations compared populations of African origin (9).

UM is typically an adult malignancy, affecting older age groups (10). The median age at diagnosis has been reported to be approximately 62 years (2), with an incidence rate that tends to increase progressively up to 70 years of age, and then levels off after 75 years of age $(4,5,10,11)$. The mean age at diagnosis for UM seems to decrease from 59-62 years of age in Caucasians, $(4,12)$ to 55 years in Japanese, 51 years in Taiwanese and 45 years in Chinese populations (13-15). UM is uncommon in children and extremely rare in newborns; congenital melanoma is also rare $(11,16,17)$. Shields et al investigated the incidence rate of UM in children and teenagers, and demonstrated that $50 \%$ of cases were $>15$ years of age, $35 \%$ were between 10 and 15 years, $11 \%$ between 5 and 10 years, and only $3 \%$ of cases were between 0 and 5 years of age at the time of diagnosis (17).

The incidence of UM appears to be related to sex as well $(2,10)$. Population-based studies have demonstrated a higher age-adjusted incidence in the male sex compared to females, with a $20-30 \%$ greater rate in males $(1,4)$. An Australian population-based study found this difference to be more prominent in the population which was $\geq 65$ years of age, whilst there was no significant difference in sex as regards the incidence of UM when considering the population $<65$ years of age (18).

\section{Risk factors}

Several risk factors have been associated with the development of UM. Host susceptibility variables, such as fair skin color, inability to tan and light eye color have been significantly associated with UM, with a risk ratio of 1.80, 1.64 and 1.75 , respectively (19). This association is likely to be related to the poor amount of melanin in the skin and eyes. It has been assumed that a poor amount of melanin is present in the choroid and retinal pigment epithelium, leading to an increased susceptibility to ultraviolet light and a higher risk of developing UM (19). Oculodermal melanocytosis, also known as Nevus of Ota, represents a relevant risk factor for developing UM (20,21). This condition is characterized by an abnormal congenital hyper-pigmentation within the V1/V2 trigeminal nerve area, and can involve periocular skin, orbit, uvea, sclera and conjunctiva, as well as the palate, meninges and tympanic membrane $(20,21)$. Usually this condition is unilateral and, is mostly confined to the eye. Oculodermal melanocytosis is 35 -fold more common in patients with UM compared to the healthy population: The incidence rate among the Caucasian population is 0.04 vs. $1.4 \%$ to $3 \%$ in patients with UM $(20,21)$. A Caucasian patient affected by oculodermal melanocytosis presents a lifetime risk for developing UM equal to 1:400 (22). The presence of atypical cutaneous nevi and intraocular nevi has been also associated with the development of UM. In particular, the risk of developing UM is 4-10-fold higher in patients affected by atypical cutaneous nevi than in the healthy population $(23,24)$. Intraocular nevi, such as iris nevi and choroidal nevi, are considered risk factors for UM. Iris nevi have been reported to have a potential risk of malignant transformation, although the rate of this transformation has not been clearly established, ranging from $2-5 \%(25,26)$. Predictive factors for an iris nevus to transform into an iris melanoma have been summarized in the ABCDEF acronym: A stands for young age; B stands for blood; $\mathrm{C}$ stands for clock-hour (inferior location); D stands for diffuse flat shape; E stands for ectropion uveae; F stands for feathery margins (26). Choroidal nevus is a common finding in the healthy population, with an incidence rate of approximately 5\% in the United States (27). Based on the concept that all melanomas originate from a nevus, the rate of transformation of a choroidal nevus into melanoma has been reported as 1:8845, increasing to 1:3664 in the older aged cohort (80-84 years old) (28). Predictive factors for a choroidal melanoma to become malignant are a thickness of $>2 \mathrm{~mm}$, the presence of subretinal fluid, presence of orange pigment, proximity to optic disc, the absence of drusen or halo and ultrasonographic hollowness $(29,30)$.

A further relevant risk factor for the development of UM is the mutation of the onco-suppressor gene, BRCA1 associated protein 1 (BAP1) (10,31). BAP1 is located on chromosome 3. The mutation of this gene has been associated with a hereditary cancer syndrome. Tumors, such as malignant mesothelioma, basal cell carcinoma, cutaneous melanomas, UMs and renal cell carcinoma, can be developed following either the somatic or germline mutation of BAP1 (31). In the case of germline mutation, the tumors seem to be less aggressive than those without this mutation (31). BAP1 has been found mutated in up to $47 \%$ of UM cases (32). Of note, patients affected by $\mathrm{UM}$ present a higher risk compared to the general population 
(approximately $\geq 11 \%$ ) of a developing a secondary cancer, including renal cell carcinoma and cutaneous melanoma, which could be related to germline BAP1 mutations (2).

Sunlight ultraviolet exposure has been clearly identified as a risk factor for skin melanomas (33), although there is still debate as to whether this could represent a risk factor for UM: Some authors support this hypothesis (34), while others refuse this (35). A previous meta-analysis revealed that chronic occupational natural ultraviolet light exposure was a borderline non-significant risk factor for UM, whereas geographic latitude and outdoor leisure UV exposure were not significant (35). Conversely, welding was found to be a significant variable associated with the development of UM (35). As regards other artificial lights, blue light exposure has been hypothesized to play a role in the oncogenetic process and progression of UM (36). In addition, occupational cooking seems to be associated with a higher risk of developing UM (37).

\section{Clinical characteristics}

Patients affected by UM can be asymptomatic (up to $30 \%$ of cases), with this malignancy being an incidental finding at the time of diagnosis (38). Symptoms, when preset, are related to the location of the tumor. Iris melanomas are relatively uncommon (3-5\% of UMs) and diagnosis is mostly secondary to heterochromia, i.e., changes in iris color, and corectopia, i.e., abnormality in pupil shape, which is present in approximately $45 \%$ of cases $(10,39)$. Usually, the tumor is located in the inferior quadrant of the iris (45\% of cases) and can cause secondary glaucoma (direct or indirect obstruction to trabecular outflow), ectropion uveae, angle seeding and bleeding with hyphema (10). In some cases, it can be complicated by extraocular extension (3\%) (39). Extraocular extension, as well as high intraocular pressure have been shown to be variables associated with metastatic disease (39). Clinically, an iris melanoma can present several types of configuration and levels of pigmentation (from amelanotic to pigmented). In the majority of cases, iris melanoma is circumscribed, while in a few cases, approximately $10 \%$, it can be diffuse $(39,40)$. Diffuse iris melanoma is an infiltrative form, undefined and flat, which can prove difficult to diagnose: The presence of ipsilateral ocular hypertension and acquired heterochromia of the iris are typically associated with this condition (40). A rare variant of diffuse iris melanoma is the ring melanoma of the anterior chamber, a tumor that arises from the angle and tends to infiltrate the angle structures $>360$ degrees, with a ring pattern of growth (minimal extension towards iris or ciliary body) (41). The main symptom is unilateral glaucoma and diagnosis is very difficult (depends on careful gonioscopy and ultrasound biomicroscopy) (41).

When it comes to choroidal and ciliary body melanomas, also known as posterior UMs, the main symptoms are blurriness (38\% of cases), and floaters and flashing lights (7 and 9\%, respectively). Less commonly, visual field loss, metamorphopsia and pain have been reported (38). The diagnosis of ciliary body melanomas is usually delayed due to their location and as symptoms tend to appear only when the tumors are large (10). A study including 492 ciliary body melanomas found at baseline, a mean tumor base of $11.7 \mathrm{~mm}$ and a mean thickness of $6.6 \mathrm{~mm}$, proving that the size of these tumors at the time of diagnosis was relatively large (42). However, the same study also included 7,256 choroidal melanomas, presenting a baseline mean base of $11.3 \mathrm{~mm}$ and a mean thickness of $5.5 \mathrm{~mm}$ (42). The average choroidal melanoma thickness at diagnosis has exhibited a decreasing trend from $5.5 \mathrm{~mm}$ in the $1970 \mathrm{~s}$, to $4.5 \mathrm{~mm}$ in the $1990 \mathrm{~s}$, to $4 \mathrm{~mm}$ in more recent times (43) This demonstrates the efforts in improving the early diagnosis of the tumor. Choroidal melanoma appears as a pigmented lesion in $55 \%$ of cases; in $15 \%$ of cases is non-pigmented and in $30 \%$ of cases has mixed pigmented and non-pigmented features (43). The most common configuration of choroidal melanoma is dome-shaped, in $75 \%$ of cases. When the tumor grows, breaking through Bruch's membrane, it acquires a typical mushroom-shaped configuration (20\% of cases) (43). Less commonly, in approximately 5\% of cases, choroidal melanoma presents a diffuse configuration, which can make diagnosis more challenging (43). Orange pigment and subretinal fluid are typically associated with choroidal melanomas. The tumor can cause bleeding with subsequent vitreous hemorrhage, which can obscure the view of the fundus. Neovascular glaucoma can develop in advanced cases (43).

\section{Diagnosis}

The diagnosis of UM is based on a clinical examination and ancillary tests (Table I). The diagnosis of iris melanoma relies on slit lamp biomicroscopy, anterior segment-optical coherence tomography (as-OCT) and ultrasound biomicroscopy (UBM). In particular, UBM and as-OCT are helpful tools for the assessment of the posterior extension of the tumor (10). Gonioscopy is important to evaluate possible angle involvement (10). Transillumination may help to evaluate ciliary body involvement (10). A thorough fundus examination is also required to assess retinal and choroidal condition. The diagnosis of iris melanoma can be challenging, in particular in cases of small/circumscribed lesions and diffuse melanomas. Differential diagnosis includes most commonly, iris nevus, as well as less common lesions, such as cysts, metastasis, leiomyoma, melanocytosis and inflammatory conditions (granulomas) (44,45). The differential diagnosis of diffuse melanomas includes diffuse iris nevus, congenital heterochromia, congenital, ectropion iridis, melanocytomalytic glaucoma, pigmentary glaucoma, siderosis and iridocorneal endothelial syndrome (40). Photographic documentation plays a relevant role in case of small lesion with a basal diameter $<3 \mathrm{~mm}$, providing information on tumor growth during the follow-up. As reported above, the ABCDEF rule is useful in differentiating an iris nevus from a melanoma. In doubtful cases, such as small lesions, fine-needle biopsy could be very helpful in the diagnostic process, with a low risk of complications and a good rate of adequate sampling (46).

The diagnosis of ciliary body melanomas can prove difficult when the lesion is small, as the location does not allow for a good visualization (10). A good scleral indentation during fundus examination could be useful to bring into the view these tumors. However, in the majority of cases, tumors are diagnosed when are large with choroidal or iris invasion (10). Transillumination may help to visualize large lesions. A valuable examination for detecting small ciliary body melanomas $(<4 \mathrm{~mm})$ is UBM, which is useful in follow-up as well (47). 


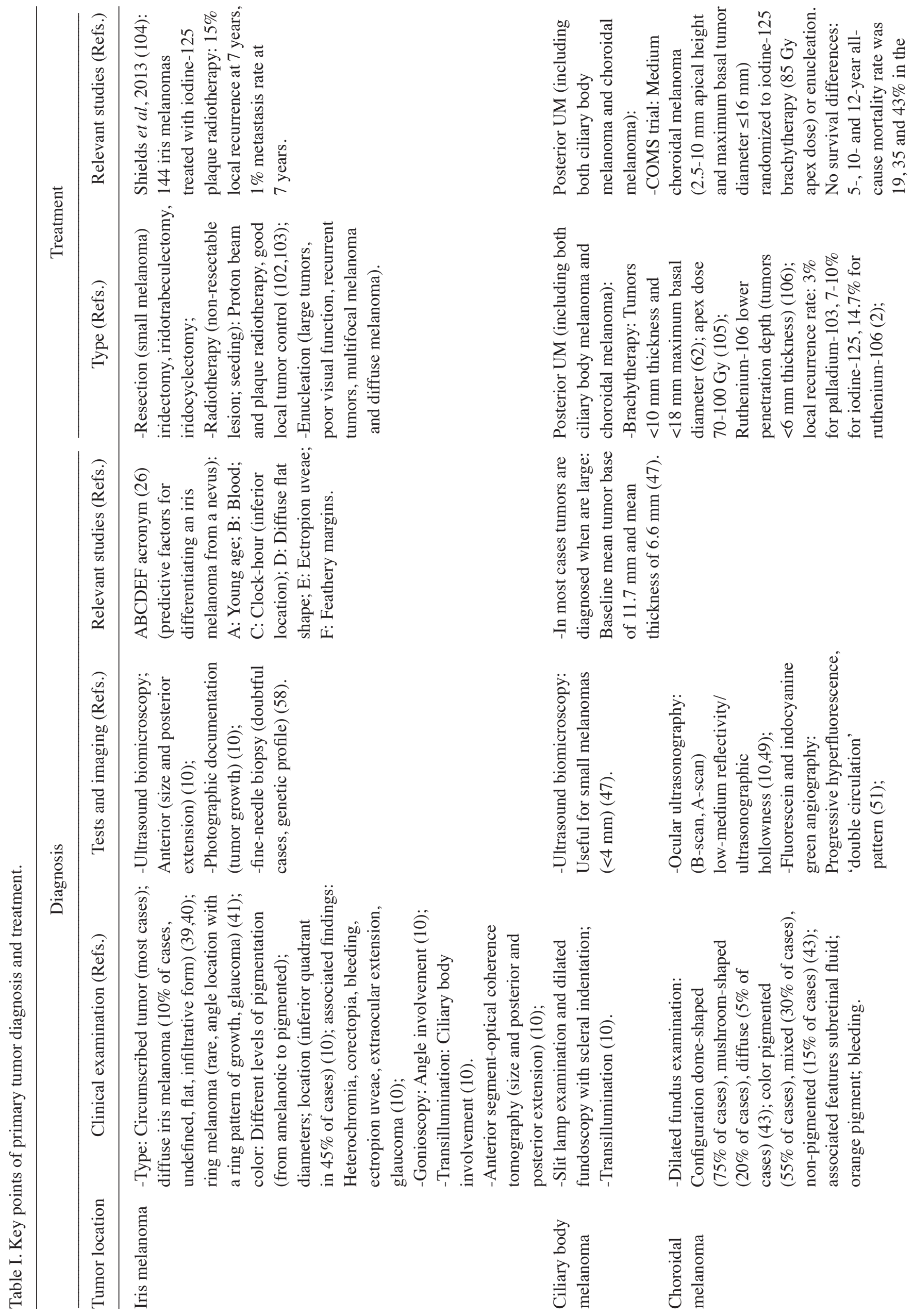




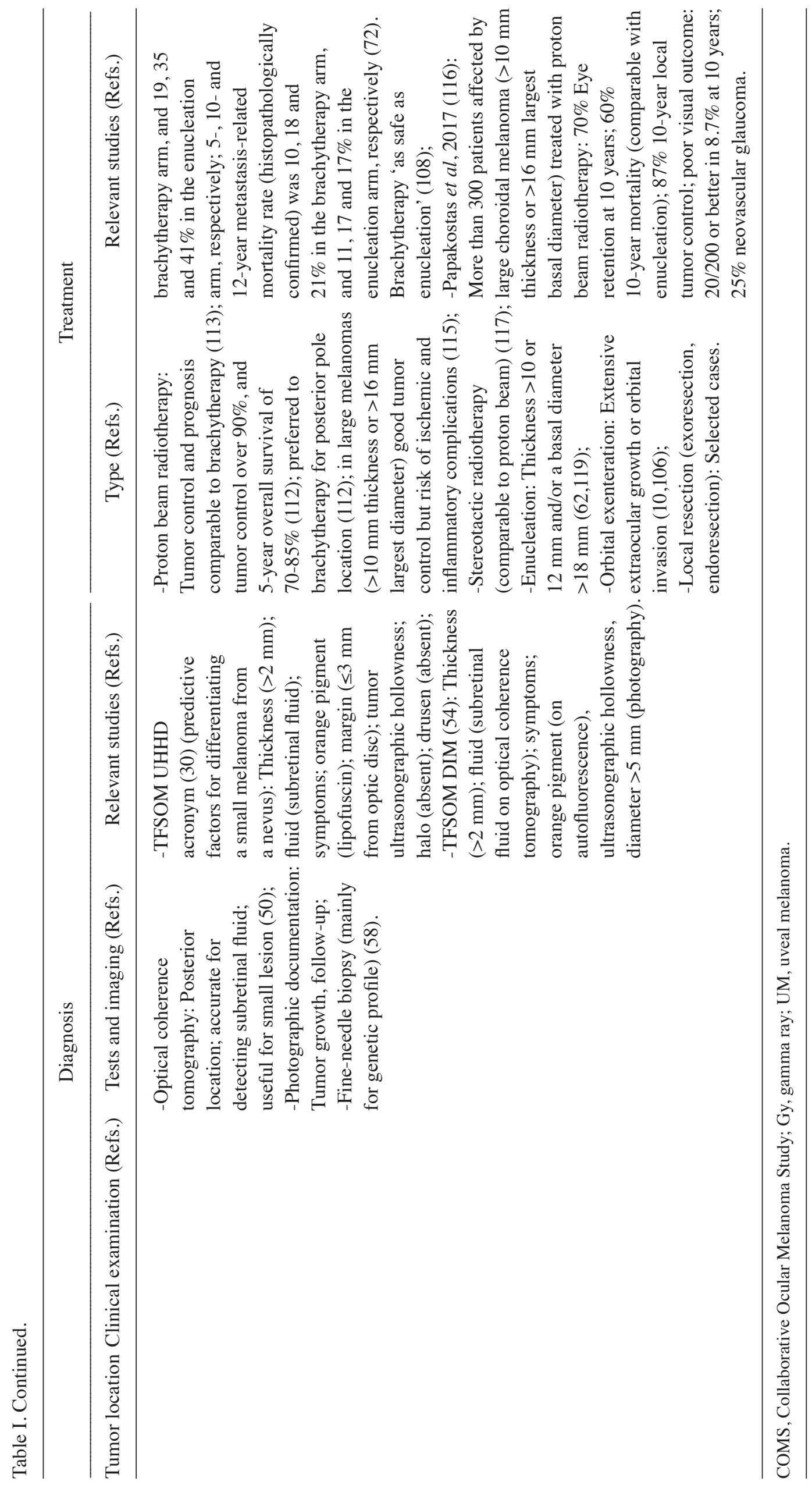


The diagnosis of choroidal melanoma depends mostly on fundus examination with indirect ophthalmoscopy. The most important test in the diagnostic process is represented by ocular ultrasonography $(10,48)$. In particular, B-scan ultrasonography provides information on tumor size and extension. A-scan ultrasonography provides valuable information on the reflectivity of the lesion. The presence of acoustic hollowing is a typical characteristic of UM (10). Ossoinig considered the presence of low-medium reflectivity as one of the cardinal hallmark of a melanoma lesion (49). Other A-scan characteristics may be a quite regular internal structure with spikes showing a similar height or a decreasing height, solid consistency and sign of vascularization such as a spike showing fast, vertical motion with flickering (49). Of note, A-scan ultrasonography has a limited use in the case of very shallow lesions, with a thickness $<1.5 / 2 \mathrm{~mm}$. Clinical examination and information provided by ultrasonography, when carried out by an ocular oncology expert, ensure a high level of accuracy, minimizing the necessity for biopsy (48). Other useful tests are OCT imaging, fluorescein angiography and indocyanine green angiography. Enhanced deep imaging OCT is helpful for studying small lesion ( $<3 \mathrm{~mm}$ in diameter) which are difficult to study with other methods (50). Furthermore, it has a high accuracy in detecting subretinal fluid and may help to differentiate small choroidal malanomas from other lesion, including nevi (10). However, its use may be limited when it comes to lesions with a thickness $>3 \mathrm{~mm}$ (10). Fluorescein angiography may be characterized by a progressive hyperfluorescence which may last for $>30-40 \mathrm{~min}$. In the case of Bruch's membrane break, the examination can reveal a typical 'double circulation' pattern, due to the presence of tumor vessels underneath the retinal vasculature (51). Indocyanine green angiography is more useful in showing intra-lesion vasculature, with the average peak of hyperfluorescence at $18 \mathrm{~min}$ (52). The use of computed tomography and magnetic resonance imaging with the purpose of studying choridal melanomas has been investigated (10); however, their application in clinical practice is very limited. The most common differential diagnosis of choroidal melanomas is the choroidal nevus. Others can be congenital hypertrophy of the retinal pigment epithelium (CHRPE), peripheral eccentric choroidal neovascular membrane, choroidal hemangioma, hemorrhagic detachment of pigment epithelium/retina (53). Differentiating a small choroidal melanoma from a choroidal nevus may prove very difficult in some cases. Shields et al provided a mnemonic acronym which can be useful in daily practice: 'To Find Small Ocular Melanoma Using Helpful Hints Daily (TFSOM UHHD), which stands also for thickness ( $>2 \mathrm{~mm}$ ), fluid (subretinal fluid), symptoms, orange pigment (lipofuscin), margin ( $\leq 3 \mathrm{~mm}$ from optic disc), ultrasonographic hollowness, halo (absent), drusen (absent) (30). Additionally, it has to be taken into account that a few number of choroidal nevi may transform into choroidal melanomas $(<1: 8,000)(28)$. When one of the TFSOM UHHD factor is present, there is a $38 \%$ risk for the lesion to transform into melanoma at 5 years, increasing to $50 \%$ when at least two factors are present $(29,30)$. If the lesion has the following 3 TFSOM UHHD factors, such as a thickness of $>2 \mathrm{~mm}$, a location close to the disc and symptoms, the risk for transformation into melanoma at 5 years increases to $69 \%(29,30)$. A choroidal nevus with drusen (signs of chronicity), a thickness
$<2 \mathrm{~mm}$ and no other TFSOM UHHD factor, can be considered 'low-risk'. The presence of one or more TFSOM UHHD factors indicates a 'high-risk' nevus (10). Lesions with $\geq 2$ TFSOM UHHD factors are likely to represent small choroidal melanomas and treatment should be indicated $(29,30)$. Recently, TFSOM UHHD has been updated, introducing the use of multimodal imaging. The new acronym 'To Find Small Ocular Melanoma Doing Imaging (TFSOM DIM) stands for thickness ( $>2 \mathrm{~mm}$ on ultrasonography), fluid (subretinal fluid on spectral domain-OCT), symptoms, orange pigment (on autofluorescence imaging), melanoma ultrasonographic hollowness, diameter $>5 \mathrm{~mm}$ (photography). The 5-year risk for transformation of a nevus into melanoma was $22 \%$ with two factors, $34 \%$ with three factors and $51 \%$ with four factors (54). Therefore, documenting with fundus photograph a choroidal nevus/indeterminate lesion, which appears suspicious, plays a relevant role for detecting lesion growth during the follow-up. Data from the Collaborative Ocular Melanoma Study (COMS) demonstrated a misdiagnosis rate of approximately $0.5 \%$ (55). This finding suggests that the diagnosis of UM can be based on clinical examination and tests. However, the COMS applied strict eligibility criteria, which could have had an influence on the rate of misdiagnosis. Indeed, other studies have found diagnostic fine-needle biopsy necessary in $1-9 \%$ of cases $(56,57)$. The biopsy of intraocular tumors is debated due to the risk of tumor dissemination, as well as the risk of ocular complications and inadequate sampling. However, currently, tumor sampling has become more diffuse, usually not for confirming the diagnosis, but with the purpose of analyzing the genetic profile for assessing metastatic risk and prognosis (58). For choroidal melanomas, fine needle aspiration biopsy (FNAB) is performed using particular precautions to prevent tumor seeding as well as subsequent application of radiotherapy, which can help to sterilize seeded cells (58).

\section{Staging}

The 8th edition of the American Joint Committee on Cancer (AJCC) classification was published in 2016 and provides the classification of UM as well (59). This is an updated version of the 7th edition (60). However, the differences between the two editions are minimal. The widespread T (tumor), N (node), M (metastasis) staging has been used also for UM. Two classifications have been developed, one for iris melanoma, and one for choroidal and ciliary body melanoma due to different primary tumor staging $(\mathrm{T})$. In either case, T0 refers to cases with no evidence of primary tumors and Tx to cases where primary tumor cannot be evaluated. Iris melanoma primary tumor (T) classification is presented in Table II.

Primary tumor (T) classification for choroidal and ciliary body melanomas depends on tumor size (thickness and largest basal diameter), as well as ciliary body involvement and extraocular extension (59). Primary tumor classification according to tumor size is displayed in Table III.

All $\mathrm{T}$ values can be featured by a letter from ' $a$ ' to ' $d$ ', where ' $a$ ' indicates nor ciliary body involvement neither extraocular extension, and ' $b$ ' indicates ciliary body involvement without extraocular extension; 'c' indicates no ciliary body involvement, but a $\leq 5 \mathrm{~mm}$ extraocular extension; and ' $\mathrm{d}$ ' indicates both ciliary body involvement and a $\leq 5 \mathrm{~mm}$ extraocular 
Table II. Iris melanoma primary tumor (T) classification according to the American Joint Cancer Committee (AJCC 8th edition) (59).

\begin{tabular}{lll}
\hline Primary tumor $(\mathrm{T})$ classification & Explanation & Sub-stages
\end{tabular}

T1

$\mathrm{T} 2$

T3

T4
Tumor limited to the iris

Tumor confluent with or extending into the ciliary body, choroid, or both

Tumor confluent with or extending into the ciliary body, choroid, or both, with scleral extension

Tumor with extrascleral extension
T1a: not $>3$ clock hours in size

T1b: $>3$ clock hours in size

T1c: T1 with secondary glaucoma

T2a: Confluent with or extending into the ciliary body, without secondary glaucoma

T2b: Confluent with or extending into the ciliary body and choroid without secondary glaucoma

T2c: Confluent with or extending into the ciliary body, choroid, or both, with secondary glaucoma

T4a: Extrascleral extension $\leq 5 \mathrm{~mm}$ in diameter T4b: Extrascleral extension $>5 \mathrm{~mm}$ in diameter

The information presented in the table is derived from a previous study (59).

Table III. Primary tumor (T) classification for choroidal and ciliary body melanoma based on thickness and largest diameter (59).

\begin{tabular}{|c|c|c|c|c|c|c|c|}
\hline \multirow[b]{2}{*}{ Thickness } & \multicolumn{7}{|c|}{ Largest basal diameter, $\mathrm{mm}$} \\
\hline & $\leq 3$ & $3.1-6$ & $6.1-9$ & $9.1-12$ & $12.1-15$ & $15.1-18$ & $>18$ \\
\hline$\leq 3 \mathrm{~mm}$ & 1 & 1 & 1 & 1 & 2 & 2 & 4 \\
\hline $3.1-6 \mathrm{~mm}$ & 1 & 1 & 1 & 2 & 2 & 3 & 4 \\
\hline $6.1-9 \mathrm{~mm}$ & 2 & 2 & 2 & 2 & 3 & 3 & 4 \\
\hline $9.1-12 \mathrm{~mm}$ & 3 & 3 & 3 & 3 & 3 & 3 & 4 \\
\hline $12.1-15 \mathrm{~mm}$ & 3 & 3 & 3 & 3 & 3 & 4 & 4 \\
\hline$>15 \mathrm{~mm}$ & 4 & 4 & 4 & 4 & 4 & 4 & 4 \\
\hline
\end{tabular}

The information presented in the table is derived from a previous study (59).

extension (59). Additionally, the T4e category includes any tumor size with an extraocular extension of $>5 \mathrm{~mm}(59)$. Regional lymph nodes (N) include preauricular, submandibular and cervical sites. Node assessment applies to tumors with extrascleral growth and conjunctival involvement. Nx includes cases where nodes cannot be evaluated; NO indicates absence of node metastasis; and N1 indicates the presence of node metastasis or discrete tumor deposits in the orbit; the N1 stage is classified into N1a (metastasis in one or more regional lymph nodes) and N1b (no positive regional lymph nodes, but the presence of discrete tumor deposits in the orbit that are not contiguous to the eye). Distant metastases are evaluated in the ' $\mathrm{M}$ ' category: M0 indicates no metastasis; M1 indicates the presence of distant metastasis ('a' $\leq 3 \mathrm{~cm}$ metastasis; ' $\mathrm{c}$ ' 3.1-8 cm metastasis; 'c'>8.1 cm metastasis) (59). The AJCC anatomic stage is presented in Table IV.

A further classification depends on the histological grade (G) of the tumor. Basically, there are three histopathologic types of UMs, according to their cytological composition:
Spindle cell UM (>90\% spindle cells); epithelioid cell UM (>90\% epithelioid cells); mixed UM, consisting of $<90 \%$ spindle cells and $>10 \%$ epithelioid cells (59). Spindle cells feature ovoid nuclei and their growth exhibits a compact and cohesive pattern. Epithelioid cells are pleomorphic, with larger and irregular shape compared to spindle ones. The growth pattern of their nuclei and nucleoli is less cohesive compared to spindle type; their cytoplasm is acidophilic (59). Gx indicates cases where the grade cannot be evaluated. G1 includes spindle cell UM; G2 mixed cell UM; G3 epithelioid cell UM (59).

At the time of diagnosis, it is mandatory to carry out imaging tests to identify systemic metastases, as the presence of metastases has a relevant effect on the management plan. In the past, baseline imaging consisted of abdominal ultrasonography and chest radiography. Given the low sensitivity of those tests (61), baseline modern imaging work-up for ruling out metastases includes usually one of the following protocols: Computed tomography (CT) of chest and abdomen; chest CT 
Table IV. Anatomic stage according to AJCC cancer staging manual, 8th edition (59).

\begin{tabular}{lccc}
\hline Stage & T & N & M \\
\hline I & T1a & N0 & M0 \\
IIA & T1b-d & N0 & M0 \\
& T2a & N0 & M0 \\
IIB & T2b & N0 & M0 \\
& T3a & N0 & M0 \\
IIIA & T2c-d & N0 & M0 \\
& T3b-c & N0 & M0 \\
& T4a & N0 & M0 \\
IIIB & T3d & N0 & M0 \\
& T4b-c & N0 & M0 \\
IIIC & T4d-e & N0 & M0 \\
IV & Any & N1 & M0 \\
& Any & N1 & M1a-c \\
\hline
\end{tabular}

The information presented in the table is derived from a previous study (59).

and liver magnetic resonance imaging (MRI); whole body positron emission tomography-CT (62).

\section{Prognosis}

UM presents a high mortality rate and up to $50 \%$ of cases metastasize $(2,63)$. A large study including both iris and posterior melanomas revealed a metastatic rate of $15 \%$ at 5 years and $25 \%$ at 10 years (42). The most common metastasis site is the liver (60-89\%), followed by the lungs (24-29\%), skin and soft tissue $(11-12 \%)$, bone $(8-17 \%)$ and lymph nodes $(11 \%)(63,64)$. The prognosis of UM has been related to several variables. First, location has been shown to have an influence on prognosis. Iris melanoma has a mortality rate 5-10-fold lower than posterior UM. In a review article of $>8,000$ cases of UM, the 10 -year metastasis disease was shown to be $33.4 \%$ for ciliary body melanomas, $25 \%$ for choroidal melanomas and $6.9 \%$ for iris melanomas (42). The better prognosis of iris melanoma can be explained by factors including a lower biologic activity, younger age and smaller size $(65,66)$. The cumulative proportion of metastatic disease and mortality at 5 years has been found to be 5.2 and $2.2 \%$, respectively, increasing to 8.8 and $3.3 \%$ at 10 years, respectively (39). In the case of iris melanoma, factors predicting melanoma-related metastasis are an older age, increased thickness, secondary glaucoma, angle involvement and extraocular extension $(39,42,67)$. A study investigating the very long-term prognosis of patients with posterior UM reported a melanoma-related mortality rate of $31 \%$ at 5 years, $45 \%$ at 15 years and $49 \%$ at 25 years $(68)$. The COMS study, which included choroidal melanomas and featured strict eligibility criteria excluding peripapillary tumors and predominately ciliary body tumors, reported a cumulative metastasis rate of $25 \%$ at 5 years and $34 \%$ at 10 years (64). Following the development of metastasis, the mortality rate was $80 \%$ within one year and $92 \%$ within two years (64).
Several factors have been investigated with the purpose of assessing their possible influence on the prognosis of UMs, and the role of some is still debated (10). For instance, whether age and sex may have an influence on the prognosis is not yet completely clear. It seems that a younger age may exert a protective effect against metastatic disease as the immune response is more robust, lesions tend to be smaller and genetic mutations are less common compared to older aged patients $(17,66)$. In a study including $>8,000$ patients with melanoma, Shields et al (69) reported a cumulative rate of metastasis at 10 year of $9 \%$ in patients $<20$ years of age, $23 \%$ in patients 21-60 years of age and $28 \%$ in patients $>60$ years of age; the cumulative 10 -year mortality rate was $5 \%$ in patients $<20$ years of age, $11 \%$ in patients $21-60$ years of age and $16 \%$ in patients $>60$ years of age; at 10 years, metastases were found in $0 \%$ of patients $0-10$ years of age, $10 \%$ of patients 11-20 years of age, $21 \%$ of patients $41-50$ years of age, and in $30 \%$ of patients 71-80 years of age. The authors concluded that young patients had a lower rate of metastatic disease. However, the proportion of iris melanoma was $21 \%$ in young ( $\leq 20$ years old), $4 \%$ in mid adult (21-60 years old) and $2 \%$ in older adult ( $>60$ years old) patients (69). Whether the female sex could have a better prognosis compared to the male sex remains controversial: In one study, the mortality rate at 10 years was found to be 2 -fold greater in males compared to females, and time to develop metastatic disease was shorter in males compared to females (metastatic disease at 5 years from diagnosis of UM in $84 \%$ of males compared to $50 \%$ of females) (70); however, no sex-related differences in survival analysis were found in the COMS study (71).

Tumor size has been demonstrated to have a significant effect on the development of metastases. In a large study including both iris and posterior UM, the 10 -year metastasis rate was $6 \%$ for a thickness of $0-1 \mathrm{~mm}, 12 \%$ for a thickness of 2.1-3 mm, $16 \%$ for a thickness of 3.1-4 mm, $27 \%$ for a thickness of $4.1-5 \mathrm{~mm}, 41 \%$ for a thickness of $7.1-8 \mathrm{~mm}$, and $51 \%$ for a thickness of $>10 \mathrm{~mm}$ (42). A hazard ratio of 1.06 was found for a $1 \mathrm{~mm}$ increase in thickness (42). The COMS report on the mortality outcome of medium choroidal melanomas (2.5-10 $\mathrm{mm}$ thickness and $\leq 16 \mathrm{~mm}$ largest basal diameter) revealed a similar rate of melanoma metastasis-related mortality at 10 years in both brachytherapy and enucleation arms (18 and 17\%, respectively), and depicted a larger maximum basal tumor diameter as a primary predictor of melanoma metastasis-related death (72). Likewise, the COMS report on large choroidal melanomas $(>10 \mathrm{~mm}$ thickness and $>16 \mathrm{~mm}$ diameter) revealed a melanoma metastasis-related mortality of $40 \%$ in the enucleation arm at 10 years, and depicted a larger maximum basal tumor diameter as a primary predictor of melanoma metastasis-related mortality (71). A previous meta-analysis on choroidal melanomas treated with enucleation reported a 5-year mortality rate of $16 \%$ in the case of tumors with a thickness of $<2$ or $3 \mathrm{~mm}$ and a basal diameter $<10$ or $11 \mathrm{~mm}, 32 \%$ in case of tumors with a thickness of 3-8 $\mathrm{mm}$ and a basal diameter $<15$ or $16 \mathrm{~mm}$, and $53 \%$ in case of tumors with a thickness of $>8 \mathrm{~mm}$ and a $>16 \mathrm{~mm}$ basal diameter (73).

Not surprisingly, the AJCC staging has been demonstrated to play a prognostic role. At the 10-year follow-up, tumors with a T1 stage had a $15 \%$ metastatic rate, increasing to $25 \%$ for 
T2 tumors and to $49 \%$ for T3 tumors. Melanomas with a T4 stage presented a $63 \%$ metastatic rate (74). As reported above, the location of the melanoma has a noticeable relevance in terms of metastatic risk. Overall, ciliary body melanoma could be considered the most aggressive. Ciliary body melanomas present a 2 to 4 -fold higher risk of metastasis than choroidal ones (75). The possible reasons for this higher tendency to metastasize may be related to the delay in diagnosis (ciliary body tumors are less symptomatic and, usually, are large at time of diagnosis), the relevant vascularization of ciliary body, and the higher incidence of chromosomal predisposing alterations $(10,76)$. The presence of oculodermal melanocytosis represents a risk factor for the development of UM, as well as for metastasis development in patients affected by UM (76).

Other tumor-related features that may affect prognosis are 'diffuse' configuration and extraocular extension. The risk of melanoma-related metastasis has been demonstrated to be higher in diffuse iris melanoma and diffuse choroidal melanoma compared to non-diffuse iris and choroidal melanomas, respectively (76). Extraocular extension has a significant negative effect on prognosis when $>5 \mathrm{~mm}$ : The mortality rate at 5 years has been shown to be 37,24 and $78 \%$ for patients with microscopic, small (1-4 mm) and large extrascleral extension, respectively (77). Histopathology has been shown to play a relevant role in prognostication. As regards cell type, the optimal prognosis has been associated with spindle cell melanoma, the worst with epithelioid cell type, while mixed type has an intermediate prognosis (76). UM cases with a high mitotic activity have a worse prognosis compared to those with a low mitotic activity (78). Nucleoli size is another histopathologic variable which affects prognosis. The mean diameter of the 10 nucleoli with the largest size (MLN) is used for prognostication. A large MLN predicts a poor prognosis (76). Of note, epithelioid cells are characterized by larger MLN, but MLN has been shown to be an independent factor as well (79). Tumor vascularity also has an influence on prognosis. A high microvascular density, as well as specific microvascular patterns, such as the presence of networks or loops, have been identified as predictors of a worse prognosis (76). An unfavorable prognosis has also been associated with the presence of numerous tumor-infiltrating macrophages, high insulin-like growth factor-1 receptor expression, and a high expression of human leukocyte antigen (HLA) class I and II (76).

Recently, when it comes to prognostication, further attention has been paid to cytogenetic characteristics. Usually, genetic tests are carried out on samples obtained from FNAB or enucleation specimens. Most relevant cytogenetic alterations include chromosome 3, 1, 8 and 6 (76). Chromosome 3 loss represents a predictor of a poor prognosis. In particular, the complete loss of one chromosome 3, known as monosomy 3 , has been identified as the most relevant prognostic factor, being associated with an increased risk of metastatic disease (76). In a series of $54 \mathrm{UMs}$, monosomy 3 was found in $56 \%$ of cases. Those with monosomy 3 presented a 3 -year mortality rate of 50 vs. $0 \%$ of those without monosomy 3 (80). Monosomy 3 was found in association with other unfavorable prognostic factors, such as epithelioid type, vascular loops, high mitotic activity, extrascleral extension, ciliary body location and a large diameter (76). Furthermore, BAP1 has been located on the short arm of this chromosome (3p21.1) and BAP1 mutation has been found to be a prognostic factor for metastatic disease (32). The partial or complete loss of chromosome $1 \mathrm{p}$ predicts a negative prognosis. It is usually associated with monosomy 3 , but can also occur alone (76). Concomitant monosomy 3 and chromosome $1 \mathrm{p}$ loss is by far a stronger predicting factor for metastatic disease compared to the loss of either chromosome 3 or chromosome $1 p$ (81). The most common alteration affecting chromosome 8 is a gain in chromosome number. Indeed, chromosome $8 \mathrm{q}$ gain has been found in $41-53 \%$ of UM cases, whereas a loss of chromosome $8 \mathrm{q}$ is rare (76). Similar to chromosome 1p loss, chromosome $8 \mathrm{q}$ gain can occur alone or in combination with monosomy 3 . Chromosome $8 \mathrm{q}$ gain in combination with monosomy 3 has been associated with a poorer prognosis compared to each alteration alone: The 5-year mortality rate has been reported to be $31 \%$ in cases of $8 \mathrm{q}$ gain, $40 \%$ in cases with monosomy $3,66 \%$ in cases of concomitant $8 \mathrm{q}$ gain and monosomy 3 (82). Conversely to chromosome 8 gain, chromosome 6 gain is a predictor of a good prognosis and tends to be mutually exclusive with monosomy 3 (76). The occurrence of both monosomy 3 and chromosome 6 gain has been reported only in $4 \%$ of UM (83). On the contrary, chromosome 6 loss is a predictor of an unfavorable prognosis: The loss of $6 q$ has been found in $40 \%$ of tumors with metastatic disease vs. $7 \%$ of metastasis-free melanomas (84).

Over the past years, considerable efforts have been made to improve epigenetic and transcriptomic analyses. Gene expression profiling has provided a prognostic classification of UM. This classification consists of two main classes: Class I melanomas associated with a low risk of metastasis development and class II melanomas associated with a high risk of metastatic development (85). These results were based on the analysis of the mRNA expression of 15 genes (12 target genes and 3 controls) and have been validated in a clinical setting (86). A test analyzing these 15 genes is available and can be used in clinical practice with ease, on samples obtained from enucleation, tumor resection and FNAB (87). Class I can be divided into class IA with a $2 \%$ metastatic risk at 5 years and class IB with a $20 \%$ metastatic risk at 5 years. Class II presents a $72 \%$ metastatic risk at 5 years (88). These data allow patients to be offered a personalized management based on risk stratification (88). A further point that needs to be mentioned with regards to prognostication is the concept of micrometastasis. Eskelin et al investigated the metastasis doubling time and postulated that micrometastases could begin up to 5 years prior to primary tumor treatment (89). Taking into account all these considerations, the early diagnosis and treatment of UM, including small melanomas, may represent a key strategy for a positive long-term prognosis (10).

\section{Primary tumor treatment}

The management of UM represents a multi-disciplinary challenge, involving a variety of physicians specialized in ocular oncology, such as ophthalmologists, radiologists, medical and radiation oncologists (90). It is important to note that despite improvements being made in primary tumor treatment, the metastasis rate and overall survival has remained unaltered over the past decades $(4,91)$. Once metastatic disease has been diagnosed, the overall survival is as low as roughly one year, 
as shown by a recent meta-analysis (91). In fact, patients who present with metastasis at the diagnosis of the primary tumor often do not undergo the aggressive treatment of the primary tumor (62). Primary UM treatment can be divided into two types: Globe-preserving treatment and enucleation (Table I). The former one includes radiation therapy, laser and surgical therapy. For many years the only available treatment for UM was enucleation. In the 1970s, efforts were made to develop globe-preserving alternatives (92). Subsequently, with the introduction of radiation therapy, there has been a shift towards a globe-sparing approach rather than enucleation surgery, in particular since the COMS study revealed comparable survival rate between enucleation and plaque radiotherapy in patients with medium choroidal melanomas (72). Radiotherapy tends to be the preferred treatment for small and medium UMs, whilst enucleation is usually performed for larger and more advanced melanomas (10). Tumor characteristics, as well as patient characteristics must be taken into account when selecting the appropriate treatment.

Iris melanoma treatment depends on the size of the lesion, as well as on its characteristics. A small lesion with a basal diameter $<3 \mathrm{~mm}$, with no other sign and no symptoms, that may be a nevus or a small melanoma (indeterminate lesions), can be monitored periodically with photographic documentation for evaluating possible growth (10). Small circumscribed lesions with documented growth can be treated with sector iridectomy (93). If there is an involvement of the anterior chamber, a portion of the trabecular meshwork needs to be removed as well; this type of resection is termed iridotrabeculectomy. If there is an involvement of the ciliary body, an iridocyclectomy can be performed, resecting a portion of the iris and ciliary body (10). Intraocular surgery can be associated with complications, such as hypotony, retinal detachment, lens subluxation, phthisis, endophthalmitis and sympathetic ophthalmia (93-95). Larger melanomas are usually non-resectable and treatment is based on radiotherapy or enucleation (10,96-98). In 1955, Lloyd and Ellis described the use of radioactive wires (tantalum), inserted into the eye, for the treatment of small iris melanoma (99). Subsequently, external beam and plaque radiotherapy became available for the treatment of iris melanomas. Anterior segment irradiation can be beneficial for non-resectable lesions and for extensive seeding, as treatment margins are larger compared to simple resection $(100,101)$. In a small series of patients with iris melanoma, it has been shown that proton beam and plaque radiotherapy can achieve local tumor control in up to 93\% (102) and 97\% (103) of cases, respectively. A larger study on 144 patients reported local recurrence in approximately $15 \%$ of cases at 7 years, showing an adequate local tumor control; metastasis rate at 7 years was 1\% (104). Even if radiation treatment is a globe-spearing approach, complications may be severe and sight-threatening, including corneal opacities, cataract and iris neovascularization, culminating in vision loss $(10,101)$. Enucleation surgery is usually reserved for large tumors, poor visual function, recurrent tumors, multifocal iris melanoma and diffuse iris melanoma (10). However, radiation therapy has recently exhibited good local tumor control also for both diffuse and multifocal iris melanomas $(100,101)$.

The treatment of posterior UM can be surgery, radiation therapy or laser. In general, the most common treatments are radiotherapy, including plaque brachytherapy or external beam radiation therapy, mostly used for small/medium melanomas, and enucleation surgery, mostly used for large melanomas and poor visual function (10). Other possible treatment options include surgical resection and laser treatments, such as transpupillary thermotherapy and photodynamic therapy (PDT) (2). Importantly, in the case of indeterminate lesions, which can be either a choroidal nevus or a small melanoma, an observation can represent the first approach: The patient is monitored for documented growth or TFSOM UHHD (30) risk factors (as reported above). If there is evidence of documented growth or the presence of TFSOM UHHD (30) factors, treatment should be considered (62). In some selected patients affected by small choroidal melanomas (thickness of $<3 \mathrm{~mm}$ and largest basal diameter $<10 \mathrm{~mm}$ ), usually presenting with low-grade tumor (stable or growing slowly), an advanced age, multiple comorbidities and limited life expectancy, observation can represent an alternative to the treatment. However, patients must be informed about both the risks of treatment (visual loss) and the risk of metastasis (unquantified albeit small) for observation $(62,105)$.

Radiotherapy for UM includes plaque brachytherapy, proton beam radiotherapy and photo beam radiation therapy (stereotactic radiotherapy). Radiotherapy has gained increasing popularity for the treatment of UM and has replaced enucleation surgery for melanoma of suitable size and location (62). It is a globe-preserving treatment, which ensures excellent local tumor control (2). Following the introduction of radiotherapy for the treatment of UM, the main concern of physicians was whether there was a difference in survival between radiotherapy and enucleation (106). Therefore, from 1986 to 2003, the COMS group conducted two large multicenter clinical trials comparing survival between radiotherapy and enucleation in patients affected by medium and large choroidal melanoma (72). Patients affected by large choroidal melanoma (apical height $>10 \mathrm{~mm}$ and maximum basal tumor diameter $>16 \mathrm{~mm}$ ) were randomized to enucleation alone or external beam irradiation $(20 \mathrm{G})$ preceding enucleation surgery; patients affected by medium choroidal melanoma (2.5-10 $\mathrm{mm}$ apical height and maximum basal tumor diameter $\leq 16 \mathrm{~mm}$ ) were randomized to iodine-125 brachytherapy or enucleation (107). The COMS was the largest randomized controlled trial (RCT) performed in ocular oncology, with $>2,000$ patients enrolled (107). The results revealed no survival differences at 5, 10 and 12 years between plaque brachytherapy and enucleation in patients with medium choroidal melanoma: The 5-, 10- and 12-year all-cause mortality rate was 19, 35 and $43 \%$ in the brachytherapy arm, and 19,35 and $41 \%$ in the enucleation arm, respectively; the 5-, 10- and 12-year metastasis-related mortality rate (histopathologically confirmed) was 10,18 and $21 \%$ in the brachytherapy arm and 11, 17 and $17 \%$ in the enucleation arm, respectively (72). This reassured that brachytherapy is 'as safe as enucleation' (108). However, in a number of cases, metastases developed in a very short amount of time, suggesting that systemic spread was present at the time of primary lesion treatment; this could have led to a lack of statistical power (108). Nonetheless, the conclusion of comparable efficacy in terms of survival between brachytherapy and enucleation could be considered correct (106). As regards the large choroidal melanoma arms, no differences in 
5- and 10-year tumor-related mortality were found between enucleation alone and enucleation with preoperative irradiation $(71,107)$; this finding confirmed that primary enucleation alone does not increase mortality from metastatic disease as was hypothesized by Zimmerman et al (109).

Brachytherapy is one of the most largely used conservative treatments for UM (92). Following the publication of COMS reports, brachytherapy has become the treatment of choice for suitable tumors (62). Brachytherapy is used for posterior UMs with a thickness of $<10 \mathrm{~mm}$ and a maximum basal diameter $<18 \mathrm{~mm}$. Selected iris melanomas and ciliary body melanomas ( $<10 \mathrm{~mm}$ thickness and no extensive circumferential growth) can be considered for brachytherapy as well (62). The radiation dose delivered to the tumor apex is 80-100 Gy (10). According to the 2014 consensus guidelines from the American Brachytherapy Society, the apex dose can range from 70-100 Gy (105). The apex dose in the COMS trial was 85 Gy (110). The plaque features a saucer shape and contains the radioisotope. The plaque is sutured to the sclera (positioned corresponding to the tumor) until the dose has been delivered. Plaque size has to physically exceed tumor margin by at least $2 \mathrm{~mm}$ (free-margin) (106). During the surgery, the plaque has to be positioned adequately, in relation to tumor location: Intraoperative US or transillumination are used to ensure a proper positioning; a notched plaque is used in case of juxta-papillary lesions (106). The most largely used radioisotopes are iodine-125, ruthenium-106 and palladium-103 (62). Ruthenium-106 emits beta radiation, while iodine-125 gamma radiation. Beta radiation has a lower depth of penetration compared to gamma radiation. As a consequence, ruthenium-106 can be used for tumor with a thickness $<6 \mathrm{~mm}(2,106)$. The advantage of this limited depth of penetration should be a reduced damage to eye structures (92) A previous study on 400 eyes treated with palladium-103 plaque, revealed a favorable visual outcome and local tumor control compared with ruthenium-106 and iodine-125; the mean apex dose was 73.3 Gy (for an equivalent dose, more radiation was delivered in palladium-treated tissue compared to iodine-treated) (111). The local recurrence rate has been reported as 3\% for palladium-103, 7-10\% for iodine-125 and $14.7 \%$ for ruthenium-106 (2). Local recurrence can be either re-treated with brachytherapy or treated with enucleation. A further therapeutic option suitable for minimal margin recurrence can be transpupillary thermotherapy (TTT) (62). Proton beam radiotherapy delivers high dose radiation by using charged particles and relatively sparing superficial tissues (106). Proton beam radiotherapy can be used for the treatment of both posterior UMs and iris melanomas $(96,112)$. Tantalum markers are sutured to the sclera and their distance from tumor margins, limbus and from each other, is measured for proper localization and treatment planning. Usually, a 2-mm safety margin is used. Following a simulation phase, treatment is delivered in 4 consecutive day-sessions, with a total dose of $56 \mathrm{~Gy}$ (106). In the past, the total dose amounted to 60-70 Gy, whereas more recent studies have used a dose ranging between 50 and $60 \mathrm{~Gy}$ (112). Proton beam radiotherapy for posterior UM presents comparable outcomes in terms of tumor control, systemic prognosis and visual result compared to brachytherapy (113). Proton beam radiotherapy is considered as an effective and safe treatment for UM, with a rate of local tumor control $>90 \%$, and a 5-year overall survival of $70-85 \%$ (112). Charged-particle radiotherapy could be preferred to brachytherapy for tumors with a location that may challenge plaque positioning, with also a risk of suboptimal immobilization of the plaque (for instance, posterior pole) $(112,114)$. Proton beam radiotherapy can also be used for the treatment of large tumors; however, it could be challenged by a high rate of local recurrence and a high risk of radiation-induced complications that can lead to vision loss and/or secondary enucleation. Additionally, a 'toxic tumor syndrome' has been described following radiotherapy for large tumors as a result of severe intraocular inflammation, which causes exudative and ischemic complications (115). A previous study on $>300$ patients affected by large choroidal melanoma ( $>10 \mathrm{~mm}$ thickness or $>16 \mathrm{~mm}$ largest basal diameter; $>8 \mathrm{~mm}$ thickness in case of optic nerve involvement) demonstrated that proton beam radiotherapy allowed patients to retain the eye in $70 \%$ of cases at 10 years; the 10 -year mortality $(60 \%)$ was comparable with enucleation; and the 10 -year local tumor control was $87 \%$ (116). However, visual outcome was poor, with only $8.7 \%$ of cases with a visual acuity of $20 / 200$ or better at 10 years; additionally, $25 \%$ of cases developed neovascular glaucoma; this rate increased to roughly $35 \%$ by 5 years following treatment (116). Stereotactic photon beam radiotherapy with gamma knife, cyber knife or linear accelerator, delivers high doses from multiple directions, trying to spare surrounding tissues (106). Tumor control, survival outcome and visual outcome have been reported comparable with those of proton beam radiotherapy (117).

Common sight-threatening complications from radiotherapy are radiation retinopathy, known as radiation maculopathy when affecting the macula, and radiation papillopathy, when affecting the optic disc. Radiation maculopathy and optic nerve atrophy can lead to visual loss (118). These complications are related to the radiation-induced damage to the retina and optic nerve. Tumor size and location, as well as dosimetric parameters have an influence on their development $(112,118)$. For instance, the cumulative incidence rate of radiation maculopathy has been reported as high as $64 \%$ at 5 years for tumors located within 4 disc diameters to the macula (118). Other complications of radiotherapy include glaucoma, neovascular glaucoma, cataract, vitreous bleeding, ocular surface problems, radiation-induced dry eye, keratitis, diplopia/strabismus and scleral necrosis $(10,106,112)$.

Enucleation represented the mainstay treatment for UM prior to the advent of radiotherapy (92). Thereafter, enucleation has been the second most common treatment for UM (119). In the 1970s, a concern as to whether enucleation could increase the risk of metastasis was raised due to the diffusion of the 'Zimmerman hypothesis', which based this assumption on the potential dissemination of tumor cells into the blood system at the moment of optic nerve cutting (109). As reported above, this hypothesis was disproved following the publication of the COMS findings. Indications for enucleation include the presence of a large tumor, poor visual potential and extraocular growth $(10,114)$. Enucleation is the preferred treatment for tumors with a thickness $>10$ or $12 \mathrm{~mm}$ and/or a basal diameter $>18 \mathrm{~mm}(62,119)$. For these lesions, charged-particle radiotherapy can still be offered, although high-dose irradiation carries a high risk of complications that can lead to vision loss 
and, possibly, to eye loss; furthermore, these patients have to cope with the anxiety related to possible recurrence $(62,119)$. In a series of 1,632 patients treated for UMs from 1993 to 2002 , $35 \%$ underwent primary enucleation, $31 \%$ plaque brachytherapy and $17 \%$ proton beam radiotherapy. Factors associated with primary enucleation were tumor size, proximity to the optic disc, extensive involvement of iris, angle or ciliary body (120). Orbital exenteration can be required in the case of extensive extraocular growth or orbital invasion $(10,106)$.

The local resection of the tumor represents a globe-sparing surgical treatment which may be suitable for selected patients affected by posterior UMs. Tumor resection can be based either on an external approach, known as exoresection, or on an $a b$-interno approach, known as endoresection. The exoresection of a posterior UM needs to be performed under hypotensive general anesthesia due to the high hemorrhagic risk (106). A lamellar, partial thickness, scleral flap is created around the lesion, which is 'en-bloc' excided together with the inner scleral layer. The superficial scleral flap is, then, used to close the deep opening (121-124). This surgery is not commonly performed and can be associated with sight-threating complications, such as bleeding, retinal detachment, cataract and tumor recurrence. Shields et al reported outcomes of 95 posterior UMs treated with exoresection: Retinal hemorrhage, retinal detachment and tumor recurrence/residual occurred in 35,28 and $15 \%$ of cases, respectively (121). Adjuvant plaque brachytherapy can be associated with exoresection to reduce the risk of recurrence (125). Recently, Caminal et al (126) described the outcomes of transcleral resection performed without hypotensive anesthesia and combined with vitrectomy with silicone oil and plaque brachytherapy. The authors concluded that this demanding procedure, when successful, could provide a better visual outcome compared to plaque brachytherapy. However, submacular hemorrhage, retinal detachment and ocular hypertension occurred in 16, 21 and $21 \%$ of cases, respectively (126). Endoresection involves the piecemeal removal of the tumor by using a vitreous cutter during a pars plana vitrectomy $(127,128)$. Tumor residual can be destroyed using endolaser photocoagulation. Silicone oil is used as an endotamponade. The timing of silicone oil removal is variable, ranging from 3 to 8.8 months $(127,128)$. Due to concerns regarding tumor seeding during surgical manipulation, adjuvant radiotherapy has been associated with endoresection surgery $(128,129)$. Endoresection has been proposed to treat posterior UMs with a juxta-papillary location, as radiotherapy is likely to cause radiation-induced optic neuropathy (127). Konstantinidis et al (127) reported on 71 patients with juxta-papillary UM treated with endoresection. Over a median follow-up of 4 years, local recurrence occurred in $3 \%$ of cases, and retinal detachment in $22 \%$ of cases. All-cause mortality was 9 and $20 \%$ at 5 and 10 years, respectively. The authors concluded that the procedure could be a useful alternative to irradiation for juxta-papillary melanomas (127). Endoresection has been used also in the treatment of large UMs, in combination with preoperative stereotactic radiotherapy and adjuvant plaque brachytherapy (128). Over a mean follow-up of 32 months, $15 \%$ of cases required a further vitrectomy, mainly due to retinal detachment, $5 \%$ of cases had a local recurrence, and $15.5 \%$ of cases died from metastatic disease (128).
Laser treatment for posterior UMs includes TTT and PDT. TTT delivers an infrared laser light $(810 \mathrm{~nm})$ to the tumor surface through a dilated pupil. The laser causes an increase in tumor temperature, heating its cells to $45-60^{\circ}$. As a result, tumor abnormal vessels are obliterated, leading to a necrotic process (130). This treatment can be used for small choroidal melanomas (thickness $\leq 3 \mathrm{~mm}$ ), due to limited laser penetration (maximum penetration of $4 \mathrm{~mm}$ ) (130). Tumor pigmentation may also have an influence on treatment outcome because amelanotic lesions feature poor heat absorption (131). Therefore, small pigmented lesions may be suitable for TTT. However, the use of primary TTT as a sole treatment of small choroidal melanomas has been questioned due to high rate of local recurrence, reported up to $29 \%$ of cases (132). As a consequence, TTT should be preferably used in combination with radiotherapy (106). A study including 143 patients with choroidal melanoma compared brachytherapy alone vs. brachytherapy combined with TTT: Combined treatment provided a lower recurrence rate, while the metastasis rate and overall survival were comparable (133). However, a larger study including 449 patients with choroidal melanoma revealed no difference in tumor control and vital prognosis between brachytherapy and brachytherapy combined with TTT; of note, brachytherapy alone provided a better visual outcome (134). The treatment of large UMs with proton beam radiotherapy combined with TTT could reduce the number of secondary enucleations (135). It is worth mentioning a large study on 391 patients with choroidal melanoma treated with primary TTT: Tumor recurrence occurred in $28 \%$ of patients and its predictive factors were the presence of ocular symptoms, proximity to the optic disc, subretinal fluid, greater thickness and elevation of post-treatment tumor scar (130). Common complications following TTT for UM were retinal vein occlusion (26\%), macular epiretinal membrane $(23 \%)$, macular edema (9\%) and vitreous hemorrhage (10\%) (130). In general, TTT or PDT are used only if the lesion is very small and there is a high risk of visual loss from radiotherapy (106). Of note, TTT represents a treatment option in case of tumor recurrence after brachytherapy (136).

PDT is a non-thermal laser treatment which involves the administration of a photosensitizer activated with laser light (137). This minimally invasive therapy has also been described for the treatment of ocular tumors, including choroidal melanoma (137). Following the intravenous administration of the photosensitizer and its accumulation into the tumor tissue, laser light is delivered to activate the photosensitizer. This, once activated, it exerts a direct cytotoxic effect on the tumor, causing peritumoral vasculature destruction and local inflammation, with subsequent autophagy (137). It is important to highlight that the presence of pigmented tumor is a contraindication for PDT $(137,138)$. Pigmentation seems to prevent light penetration into the lesion (137). Thus, PDT could be used for the treatment of small amelanotic melanomas ( $<4 \mathrm{~mm}$ thickness) (10). Most commonly, PDT is performed using verteporfin as a photosensitizer. Verteporfin PDT for choroidal melanoma treatment can be with either standard fluence $\left(50 \mathrm{j} / \mathrm{cm}^{2}\right.$ in $\left.83 \mathrm{sec}\right)$ or a double fluence $\left(100 \mathrm{j} / \mathrm{cm}^{2}\right.$ in $166 \mathrm{sec})(137)$. A previous review article of 6 reports including a total of 38 choroidal melanoma cases primarily treated with verteporfin PDT showed $80 \%$ tumor control over 
31 months (137). A more recent study on 12 eyes with choroidal melanoma reported tumor control in $67 \%$ of cases, while $33 \%$ failed to regress (138). PDT with indocyanine green has been used for the treatment of choroidal melanoma, exhibiting a high rate of tumor control (137). Notably, a previous study on 25 patients demonstrated good local tumor control combining both TTT and indocyanine green PDT for the treatment of small and medium choroidal melanomas (139).

\section{Surveillance and metastatic disease treatment}

Following primary tumor treatment, patients with UM need to receive periodical ocular and systemic surveillance. The aim of ocular follow-up is the early detection and management of possible local tumor recurrence and treatment-related complications. In general, close follow-up visits are scheduled in the early post-operative period, which, then, are extended to a 3- to 6-month interval for a few years; thereafter, if the clinical condition is stable, follow-up can be arranged each year (106). Local tumor recurrence is usually managed in the same manner as the primary tumor (106). The treatment of secondary orbital involvement is challenging and includes radiotherapy and surgery (excision, debulking, or exenteration) (140). The early detection of radiation-induced complications can allow their early treatment. Anti-vascular endothelium growth factor agents have been used for the treatment of radiation retinopathy, radiation maculopathy, radiation-induced optic neuropathy and neovascular glaucoma, and can help to stabilize or, in some cases, to improve clinical conditions (141-144).

As regards systemic surveillance, an ideal surveillance protocol which would define timing, duration and the type of examinations according to patient characteristics has not yet been developed $(62,106)$. Systemic monitoring is aimed at the early detection of metastasis, which could have some clinical relevance as highly selected cases of hepatic metastasis could be managed with surgical resection, resulting in an improved survival (145). In addition, no adjuvant therapy has been demonstrated to be effective in reducing the risk of metastasis (146). In this scenario, risk stratification for metastasis development may play a key role and may allow for the planning of a surveillance protocol which could be suited to individual risk $(146,147)$. As aforementioned, prognosis is dependent on multiple factors, including clinical variables and genetic prolife (GEP class). According to the GEP class, patients can be classified as low-risk (class I) and high-risk (class II) (88). Surveillance imaging tends to be focused on hepatic monitoring due to the tendency of UM to metastasize to the liver (146). Low-risk patients can be monitored with hepatic ultrasound at 6-month intervals (146). Hepatic ultrasound features a good specificity (100\%), but poor sensitivity (14\%) (61). Therefore, high-risk patients are recommended to undergo a more frequent ( $<6$-month interval) and a more intensive hepatic monitoring, which would include more sensitive and specific imaging tests, such as liver CT/MRI (146). However, other authors recommend annual liver ultrasound and physical examination for low-risk patients, and 6-monthly liver imaging (ultrasound alternated with liver/abdomen MRI) plus annual physical examination for high-risk patients (62). Low-risk and high-risk patients can be transitioned to the GP at 5 and 10 years, respectively (62).
To date, no therapy has been demonstrated to be effective for the treatment of metastatic disease in patients with UM. Metastatic UM is associated with a poor prognosis. Several chemotherapeutic drugs, including dacarbazine, cisplatin, trosulfan, temozolomide and fotemustine, have been investigated, exhibiting a low response rate and disappointing outcomes $(114,147)$. While immunotherapy has noticeably improved outcomes in metastatic cutaneous melanoma, this has not been the case for metastatic UM (148). A possible reason for such a different response to immunotherapy could be related to the different biological characteristics between cutaneous and UMs, as well as their different immunogenicity $(149,150)$. Ipilimumab has shown a response rate of approximately $5-10 \%$, with an overall survival ranging from 6 to 9.7 months (147). Nivolumab has shown in a prospective trial a $6 \%$ response rate and an overall survival of 11 months (151). A previous retrospective study reported outcomes of 89 patients treated with ipilimumab plus nivolumab, showing a $11.6 \%$ response rate and an overall survival of 15 months (152). The understanding of the molecular mechanisms involved in UM carcinogenesis and progression will contribute to the development of targeted therapy for the treatment of metastatic UM. While BRAF inhibitors, such as dabrafenib and vemurafenib, have been used in cutaneous melanoma, which typically harbors BRAF and NRAS mutations, there is no rationale for the use of these agents in UM due to the different molecular profile compared to cutaneous ones (153). Given the commonly harbored GNAQ/GNA11 mutations in UM, agents targeting downstream effectors of biological pathways GNAQ/GNA11-related, such as MEK and protein kinase C (PKC), have been investigated. However, similar to other therapeutic approaches, disappointing results have been reported and response rates, in general, are <10-15\% (114,147). MEK inhibitors include selumetinib and trametinib. Initially, the use of selumetinib in metastatic UM seemed to provide promising results: A randomized clinical trial enrolling 101 patients compared selumetinib with traditional chemotherapy and reported longer progression-free survival (PFS) and a higher response rate (14 vs. 0\%) (154). However, these quite positive outcomes failed to be achieved in a subsequent phase III randomized trial: The SUMIT trial compared selumetinib plus dacarbazine with dacarbazine alone in 129 patients with metastatic UM and revealed no significant difference in PFS between the two interventions (median PFS, 2.8 months in the selumetinib plus dacarbazine group vs. 1.8 months in the dacarbazine alone group), and no difference in response rate (3\% in selumetinib plus dacarbazine group vs. $0 \%$ in dacarbazine group) (155). Trametinib was investigated in a phase I trial enrolling 16 patients with metastatic UM and 81 patients with cutaneous or unknown primary melanoma. In patients affected by UM, trametinib revealed no objective response (0\% response rate) and a median PFS of 1.8 months (156). Trametinib was also used in combination with Akt inhibitor: A randomized trial compared trametinib alone (18 patients receiving $\geq 1$ study drug dose) vs. trametinib combined with the Akt inhibitor GSK2141795 (21 patients receiving $\geq 1$ study drug dose), revealing no difference in median PFS (15.7 weeks vs. 15.6 weeks) and only one partial response in each group (157). Another biological pathway which has been studied as a possible target in UM is the MAPK pathway, through PKC 
inhibition. Sotrastaurin, a PKC inhibitor, has shown a median PFS of 15.4 weeks, a partial response in one patient and stable disease in 55 patients (47\%) (158). Furthermore, growth factor receptors which have been found overexpressed in UM, have been studied as possible targets. Sunitinib, a C-kit inhibitor, was used in a pilot study on 20 patients with C-kit expressing metastatic UM and demonstrawted a partial response in one patient and 12 stable disease. The median PFS was 4.2 months (159). A retrospective study evaluated the use of sunitinib as an adjuvant therapy in high-risk UM and reported a longer overall survival in those receiving adjuvant sunitinib compared to historical controls (160). Cabozantinib is a multiple tyrosine kinase receptor inhibitor, including c-MET, Axl and VEGF. This has been used in the treatment of metastatic UM. Very recently, the results of a RCT comparing cabozantinib vs. dacarbazine or temozolomide, have been published and have demonstrated no improvement in PFS in patients treated with cabozantinib (161). Sorafenib, multi-kinase inhibitor, was used in a trial enrolling 152 patients with metastatic UM: Of the 118 patients evaluable for response, $32.2 \%$ exhibited progression, $1.7 \%$ had a partial response, and $66.1 \%$ had stable disease. Patients with stable disease were randomized to sorafenib continuation or placebo, with a median PFS significantly longer in sorafenib arm (5.5 vs. 1.9 months) (162).

Since the liver represents the most common site for UM metastasis, several liver-directed treatments have been investigated. A recent meta-analysis of trials (phase Ib-III) in metastatic UM revealed that liver directed treatments were associated with a longer overall survival and PFS compared to other therapies (chemotherapy, immunotherapy and targeted therapy) (163). Liver directed treatments include surgical resection, stereotactic radiotherapy, radiofrequency ablation, regional chemotherapy and embolization $(114,164)$. Surgical resection could be a therapeutic option in very selected cases. A study including 155 patients with liver metastases from UM reported that $11 \%$ of patients underwent liver resection, with a better survival compared with those who did not receive surgical resection (145). Regional chemotherapy includes hepatic intra-arterial infusion and isolated hepatic perfusion (IHP). Fotemustine has been shown to have a better response rate (10.5 vs. $2.5 \%)$ and longer PFS (4.5 vs. 3.5 months) when administered as intra-arterial perfusion compared as intravenously, but with no difference in overall survival (165). Isolated hepatic perfusion is based on the isolation of liver blood supply from systemic circulation with the purpose of delivering high-dose chemotherapy and reducing at the same time systemic exposure. A retrospective study on 18 patients treated with percutaneous IHP with melphalan reported a median overall survival of 9.6 months and a median PFS of 12.4 months (166). Embolization treatment modalities include chemoembolization, radioembolization and immunoembolization (164). A recent prospective trial investigated radioembolizaton in two groups of patients: Treatment-naïve patients and patients who exhibited progression following immunoembolization. In the treatment-naïve group, median PFS was 8.1 months and median overall survival 18.5 months; no case of complete response was found, but 20 out of 23 patients had a partial response or stable disease. In the group resistant to immunoembolization, the median PFS was 5.2 months, and the median overall survival was
19.2 months; there was no case of compete response, but 14 out of 24 patients had partial response or stable disease (167).

\section{Genetic and epigenetic features in uveal melanoma}

Genetic and epigenetic characteristics of tumors have been given ever-increasing attention over the past years, not only due to their relevant role in the carcinogenesis process, but also as they can provide new insight into tumor behavior (168). This can potentially allow the development of reliable biomarkers and novel therapeutic targets, leading to new breakthroughs in the management of UM. Genetic alterations affect directly and permanently the DNA sequence and include the following: Chromosomal aberration, copy number variation (CNV), mutations either somatic or germline and single nucleotide polymorphism (SNP). Conversely, epigenetic alterations modulate gene activity and expression without involving any changes in the DNA sequence; these include the alteration of microRNA (miRNA/miR) expression levels, DNA methylation and histone modifications (168). The interaction between genetic, epigenetic and other possible factors involved in UM carcinogenesis is illustrated in Fig. 1.

UM is a sporadic tumor, rarely exhibiting a familial inheritance (168). This is the case of tumor syndromes, such as Lynch syndrome (169) and BAP1-tumor predisposition syndrome (170). As reported above, chromosomal alterations in UM mainly affect chromosomes 1,3,6 and 8, and present a meaningful prognostic relevance. As regards somatic mutations, the most commonly mutated genes that have been identified in UM patients are GNAQ, GNA11 mainly affected by specific point mutations (p.Q209P and p.Q209L, respectively) and BAP1 that is subjected to several mutations occurring in the whole gene sequence $(88,171)$. Unlike cutaneous melanoma, UM does not harbor typical mutations in BRAF and NRAS genes $(153,172)$. The GNAQ and GNA11 genes encode for the Ga11 subunits and the Gaq subunits of $G$ proteins, respectively (171). G proteins are involved in signal transduction, controlling gene transcription and, subsequently, cell survival, growth and mortality (171). GNAQ and GNA11 are located on chromosome 9 (q21.2) and chromosome 19 (p13.3), respectively (168). These genes have been considered as driver oncogenes, representing early or initiating mutations in UM $(168,171)$. Oncogenic mutations of GNAQ and GNA11 genes are usually mutually exclusive and were found in up to $83 \%$ of Ums (173). Oncogenic mutations of these genes determine a constitutive activation of $\mathrm{G}$ proteins, which, in turn, affect downstream signaling (171). Several intracellular pathways are regulated by GNAQ and GNA11 genes, including the $\mathrm{RAF} /$ mitogen-activated protein kinase kinase (MEK)/extracellular signal-regulated kinase (ERK) pathway (174). The activation of the RAF/MEK/ERK pathway causes an overexpression of cell-cycle regulatory protein cyclin D1 (CCND1), leading to the inactivation of the retinoblastoma tumor suppressor gene (174). Mutations in this pathway have been assumed to be early or initiating events in UM carcinogenesis (174). The BAP1 gene is an onco-suppressor gene located on chromosome 3 (p21.1). Inactivating somatic mutations of BAP1 have been associated with metastatic disease: Up to $84 \%$ of metastasizing UMs harbor inactivating mutations of this onco-suppressor gene (32). As regards BAP1 function, this 


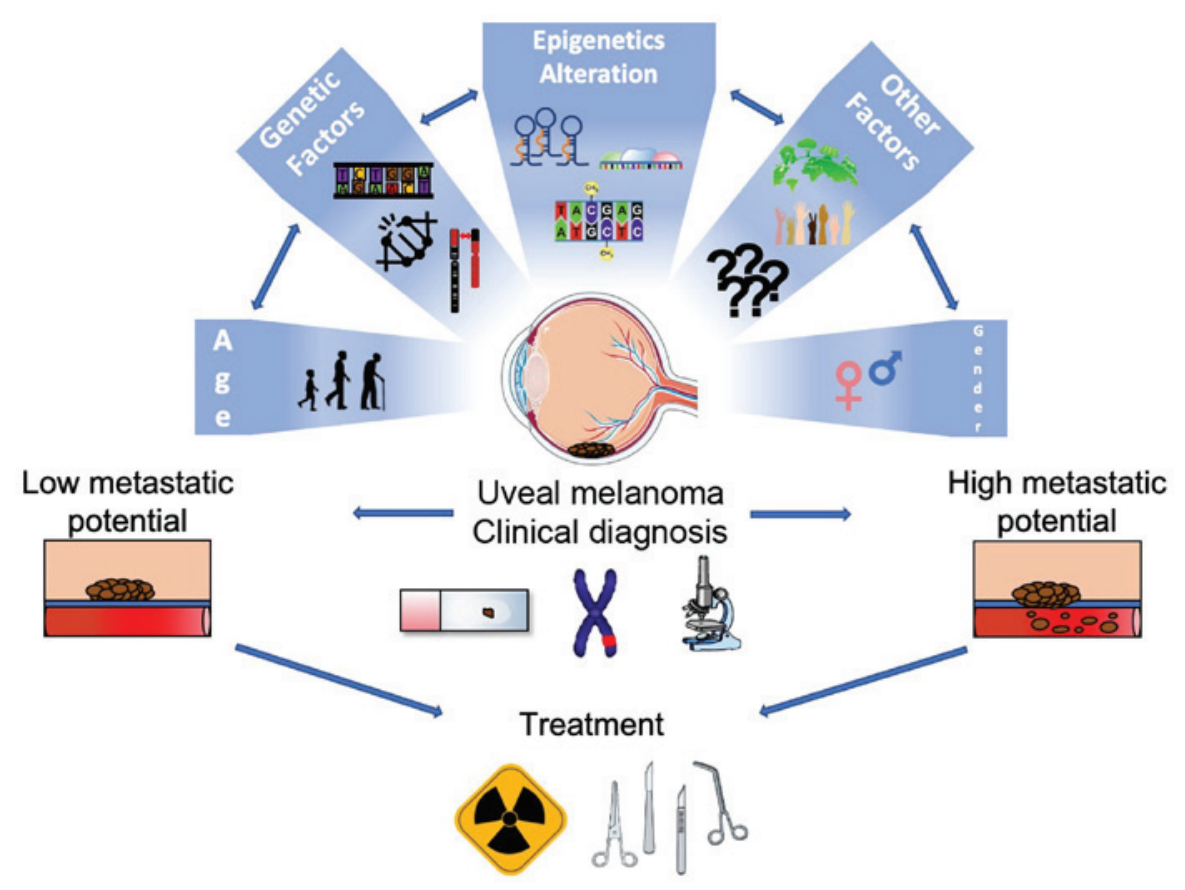

Figure 1. Schematic representation of the genetic and epigenetic alterations and risk factors involved in the development of uveal melanoma. Environmental and individual risk factors (including age, sex and ethnicity) are able to induce both genetic and epigenetic modifications responsible for the malignant transformation of choroid cells. Clinical and prognostic assessment could benefit from the analysis of genetic and epigenetic factors associated with the development of uveal melanoma.

is a deubiquitinating enzyme that regulates specific proteins. In particular, BAP1 regulates genes involved in melanocyte function and differentiation: Inactivating mutations can lead to melanocytic de-differentiation, promoting a pro-metastatic behavior. The loss of the tumor suppressor activity of BAP1 has been identified in breast and lung cancers as well (175). Of note, BAP1 mutations can also occur in germline featuring the BAP1 familial cancer syndrome, which predisposes to several cancers, including UM (176).

As regards epigenetic alterations, biological mechanisms related to miRNAs and DNA methylation have been identified in UM, whereas modest evidence on histone modification is available. The role of histone modification has been associated with BAP1 loss. It has been shown that BAP1 depletion determines a loss of differentiation in cancer cells through the hyperubiquitination of histone H2A (175). The use of histone deacetylases inhibitors proved to reverse $\mathrm{H} 2 \mathrm{~A}$ hyperubiquitination, inducing cell differentiation and inhibiting tumor growth (175). Indeed, the nuclear expression of several histone deacetylases has been found in UMs, confirming the role of this epigenetic alteration as a potential therapeutic target (177).

DNA methylation represents an important epigenetic mechanism which regulates the expression of several genes involved in UM carcinogenesis. This regulation is based on methylation/demethylation mechanisms, that is the addition/removal of a methyl group $\left(\mathrm{CH}_{3}\right)$ to/from a DNA sequence mediated by DNMT3A and TET1. It has been widely demonstrated that certain methylated DNA regions can be used as stable biomarkers, considering that DNA methylation is maintained almost unchanged during the cell replication process by DNA methyltransferase 1 (DNMT1) $(178,179)$. The functional alteration of this enzyme, together with that of other methyltransferases (DNMT3A and DNMT3B) that catalyze the de novo DNA methylation, is responsible for the global hypomethylation and hypermethylation of widespread regions of the tumor cell genome (180).

Identifying the gene regions affected by methylation phenomena is important to establish the effect that this modification determines at the transcriptional level. It is currently known that promoter methylation determines gene suppression by blocking the access of transcription factors to binding sites on the promoter $(181,182)$, while it has not yet been fully clarified the functional role of intragenic and intergenic methylation in the control of gene expression (183). On this matter, several studies have described how DNA methylation can modulate the expression of non-coding RNA, the alternative splicing, the recruitment of enhancers, and the increase of RNA polymerase activity that influences the expression levels of the genes involved (184-186). As regards UM, the hypomethylation of sites close to the preferentially expressed antigen in melanoma (PRAME) promoter has been shown to promote PRAME activation with subsequent increase in metastatic risk (187). The hypomethylation of the deleted in split hand/split foot 1 (DSS1) promoter has been found to be a frequent event in UM (188). Hypermethylation of the following oncosuppressor gene promoters has been demonstrated in UM: p16, RASSF1A, RASEF, TIMP3 and EFS (189-194). This event leads to the inactivation of these genes. The methylation of human telomerase reverse transcriptase (TERT) promoter has been described in UM. Human TERT is an oncogene which has been found to be upregulated in UM (190). TRAIL receptors DcR1 and DcR2 were found hypermethylated in both UMs and cutaneous melanomas (195). Of note, the hypermethylation of a site on chromosome 3 at BAP1 locus determines BAP1 downregulation, showing the epigenetic regulation of this gene (196).

miRNA-based epigenetic mechanisms have been also investigated in UM (197). miRNAs are non-coding RNA 
molecules, consisting of a single-stranded sequence of 18-22 nucleotides. miRNAs regulate gene expression, playing important roles in both physiological and pathological processes, such as cell proliferation, differentiation, apoptosis, organ formation, angiogenesis, extracellular matrix remodeling, etc. $(198,199)$. The dysregulation of specific miRNAs has been associated with the onset and progression of a number of types of cancer, including UM (200-203). Research in this field has exhibited marked progress. Venza et al found 96 miRNAs dysregulated in both UM and cutaneous melanoma cell lines (204). Radhakrishnan et al found specific miRNAs associated with metastatic UM, which were in association with chromosome 1,3 and 8 aberrations (205). However, Larsen et al failed to demonstrate the role of this association between chromosome alterations and miRNAs expression in predicting metastatic disease in UM (206). Worley et al demonstrated that the expression of 6 miRNAs (let-7b, miR-199a*, miR-199a, miR-193b, miR-143 and miR-652) could be used to distinguish class1 UM(low metastatic risk) from class 2 ones (high metastatic risk) with maximum sensitivity and specificity (207). Among the miRNAs involved in cell proliferation and apoptosis, which have been found abnormally expressed in UM, noteworthy are the following: miR-137 (downregulated); miR-144 (downregulated); miR-145 (downregulated); miR-92a-3p (upregulated); and miR-181b (upregulated) (208-213). Among the miRNAs involved in cell migration and invasion, which have been found abnormally expressed in UM, noteworthy are the following: miR-20a (upregulated); miR-155 (upregulated); miR-296-3p (downregulated); miR-454 (upregulated); miR-367 (upregulated); miR-21 (upregulated); miR-23a (downregulated); and miR-224-5p (downregulated) (214-221). Additionally, miR-204 and miR-145 have been found to be downregulated, whereas miR-20a, miR-17, miR-106a, miR-34a and miR-21 have been found to be upregulated in UM samples (222). Circulating levels of the following miRNAs have been found to be dysregulated in metastatic UM: miR-125b, miR-20a, miR-146a, miR-181a, miR-155 and miR-223 (223). miRNAs are also involved in the regulation of immune mediators, which can modulate UM behavior. For instance, interleukin (IL)-10 may play a role in promoting cancer as can suppress immune response against the tumor. Specific miRNAs seem to be involved in IL-10 modulation (224). miRNAs may also play a promising role in the development of therapeutic targets. For instance, genistein, an antitumor drug, has been shown to inhibit miR-27a expression and, as a result, to increase ZBTB10 gene expression (miR-27a target gene); the antitumor action may be related to the miR-27a regulatory mechanism (225). Overall, all these studies provide important insight into the involvement of miRNAs in UM development and progression, as well as in the prognosis of UM patient. However, some data are still conflicting; therefore, there is an urgent need to clarify which miRNAs are effectively involved in UM development or in specific clinical-pathological features of patients.

Recent studies have proposed the evaluation of all these genetic and epigenetic biomarkers for the early diagnosis of tumors. In particular, a previous study demonstrated how the analysis of liquid biopsy samples and circulating DNA may be useful for the early detection of genetic aberrations and epigenetic markers of precancerous and cancerous lesions (226). In this context, novel high-sensitive techniques, such as next generation sequencing and droplet digital PCR (ddPCR), have been used for the analysis of liquid biopsy samples to detect low amounts of miRNAs, circulating mutations, microbial nucleic acids, etc. (227-229).

Therefore, the analysis of both genetic and epigenetic factors in liquid biopsy and tissue samples obtained from patients with UM by using these high-sensitive techniques would contribute to the discovery of novel effective diagnostic and prognostic biomarkers for the management of UM.

\section{Conclusions}

The present review article focused on UM and collected an updated evidence on epidemiological, clinical and molecular aspects of this malignancy. It is suggested that even if UM is a relatively rare type of cancer, the prognosis remains unfavorable in a consistent percentage of cases. The treatment of the primary tumor has made significant improvements thanks to the introduction of globe-preserving approaches in the previous century. However, metastatic disease remains a critical issue for clinicians due to the lack of effective therapeutic strategies. Molecular studies have provided new insight into the genetic and epigenetic mechanisms that regulate UM biological activity. However, it seems that the available knowledge has only scratched the surface and there is hope for the identification of effective biomarkers and new therapy which can make the difference in the management of metastatic disease. This could be the breakthrough of the current century.

\section{Acknowledgements}

Not applicable.

\section{Funding}

The present study was partially supported by the Italian League Against Cancer (LILT).

\section{Availability of data and materials}

Not applicable.

\section{Authors' contributions}

MF, LF and TA conceived the study. MF and GR wrote the original draft of the manuscript. AL, MR, VB, AR, GG and LF performed the bibliography research and collected the data. RC collected data on the pathological staging of uveal melanoma. MF, GG and LF prepared the figure and tables. All authors contributed to the critical revisions, editing and reviewing of the final version of the manuscript.

\section{Ethics approval and consent to participate}

Not applicable.

\section{Patient consent for publication}

Not applicable. 


\section{Competing interests}

The authors declare that they have no competing interests.

\section{References}

1. McLaughlin CC, Wu XC, Jemal A, Martin HJ, Roche LM and Chen VW: Incidence of noncutaneous melanomas in the U.S. Cancer 103: 1000-1007, 2005.

2. Krantz BA, Dave N, Komatsubara KM, Marr BP and Carvajal RD Uveal melanoma: Epidemiology, etiology, and treatment of primary disease. Clin Ophthalmol 11: 279-289, 2017.

3. Damato B: Progress in the management of patients with uveal melanoma. the 2012 Ashton Lecture. Eye (Lond) 26: 1157-1172, 2012.

4. Singh AD, Turell ME and Topham AK: Uveal melanoma: Trends in incidence, treatment, and survival. Ophthalmology 118 1881-1885, 2011.

5. Virgili G, Gatta G, Ciccolallo L, Capocaccia R, Biggeri A, Crocetti E, Lutz JM and Paci E; EUROCARE Working Group: Incidence of uveal melanoma in Europe. Ophthalmology 114: 2309-2315, 2007.

6. Kivelä T: The epidemiological challenge of the most frequent eye cancer: Retinoblastoma, an issue of birth and death. B J Ophthalmol 93: 1129-1131, 2009.

7. Margo CE, Mulla Z and Billiris K: Incidence of surgically treated uveal melanoma by race and ethnicity. Ophthalmology 105 1087-1090, 1998

8. Shields CL, Kaliki S, Cohen MN, Shields PW, Furuta M and Shields JA: Prognosis of uveal melanoma based on race in 8100 patients: The 2015 Doyne Lecture. Eye (Lond) 29: 1027-1035, 2015.

9. Hu DN, Yu GP, McCormick SA, Schneider S and Finger PT: Population-based incidence of uveal melanoma in various races and ethnic groups. Am J Ophthalmol 140: 612.e1-612. e8, 2005.

10. Kaliki S and Shields CL: Uveal melanoma: Relatively rare but deadly cancer. Eye (Lond) 31: 241-257, 2017.

11. Singh AD and Topham A: Incidence of uveal melanoma in the United States: 1973-1997. Ophthalmology 110: 956-961, 2003.

12. Andreoli MT, Mieler WF and Leiderman YI: Epidemiologica trends in uveal melanoma. Br J Ophthalmol 99: 1550-1553, 2015.

13. Cheng CY and Hsu WM: Incidence of eye cancer in Taiwan: An 18-year review. Eye (Lond) 18: 152-158, 2004.

14. Liu YM, Li Y, Wei WB, Xu X and Jonas JB: Clinical characteristics of 582 patients with uveal melanoma in China. PLoS One 10: e0144562, 2015.

15. Sakamoto T, Sakamoto M, Yoshikawa H, Hata Y, Ishibashi T, Ohnishi $\mathrm{Y}$ and Inomata $\mathrm{H}$ : Histologic findings and prognosis of uveal malignant melanoma in Japanese patients. Am J Ophthalmol 121: 276-283, 1996.

16. Singh AD, Schoenfield LA, Bastian BC, Aziz HA, Marino MJ and Biscotti CV: Congenital uveal melanoma? Surv Ophthalmol 61: 59-64, 2016

17. Shields CL, Kaliki S, Arepalli S, Atalay HT, Manjandavida FP, Pieretti G and Shields JA: Uveal melanoma in children and teenagers. Saudi J Ophthalmol 27: 197-201, 2013.

18. Vajdic CM, Kricker A, Giblin M, McKenzie J, Aitken J, Giles GG and Armstrong BK: Incidence of ocular melanoma in Australia from 1990 to 1998. Int J Cancer 105: 117-122, 2003

19. Weis E, Shah CP, Lajous M, Shields JA and Shields CL: The association between host susceptibility factors and uveal melanoma: A meta-analysis. Arch Ophthalmol 124: 54-60, 2006.

20. Gonder JR, Ezell PC, Shields JA and Augsburger JJ: Ocular melanocytosis: A study to determine the prevalence rate of ocular melanocytosis. Ophthalmology 89: 950-952, 1982.

21. Shields CL, Kaliki S, Livesey M, Walker B, Garoon R, Bucci M, Feinstein E, Pesch A, Gonzalez C, Lally SE, et al: Association of ocular and oculodermal melanocytosis with the rate of uveal melanoma metastasis analysis of 7872 consecutive eyes. JAMA Ophthalmol 131: 993-1003, 2013.

22. Singh AD, De Potter P, Fijal BA, Shields CL, Shields JA and Elston RC: Lifetime prevalence of uveal melanoma in white patients with oculo(dermal) melanocytosis. Ophthalmology 105: 195-198, 1998

23. Hammer H, Oláh J and Tóth-Molnár E: Dysplastic nevi are a risk factor for uveal melanoma. Eur J Ophthalmol 6: 472-474, 1996.
24. Bataille V, Sasieni P, Cuzick J, Hungerford JL, Swerdlow A and Bishop JA: Risk of ocular melanoma in relation to cutaneous and iris naevi. Int J Cancer 60: 622-626, 1995.

25. Territo C, Shields CL, Shields JA, Augsburger JJ and Schroeder RP: Natural course of melanocytic tumors of the iris Ophthalmology 95: 1251-1255, 1988.

26. Shields CL, Kaliki S, Hutchinson A, Nickerson S, Patel J, Kancherla S, Peshtani A, Nakhoda S, Kocher K, Kolbus E, et al: Iris nevus growth into melanoma: Analysis of 1611 consecutive eyes: The ABCDEF guide. Ophthalmology 120: 766-772, 2013.

27. Qiu M and Shields CL: Choroidal nevus in the United States adult population racial disparities and associated factors in the national health and nutrition examination survey. Ophthalmology 122: 2071-2083, 2015

28. Singh AD, Kalyani $P$ and Topham A: Estimating the risk of malignant transformation of a choroidal nevus. Ophthalmology 112: 1784-1789, 2005.

29. Shields CL, Cater J, Shields JA, Singh AD, Santos MCM and Carvalho C: Combination of clinical factors predictive of growth of small choroidal melanocytic tumors. Arch Ophthalmol 118: 360-364, 2000.

30. Shields CL, Furuta M, Berman EL, Zahler JD, Hoberman DM, Dinh DH, Mashayekhi A and Shields JA: Choroidal nevus transformation into melanoma: Analysis of 2514 consecutive cases. Arch Ophthalmol 127: 981-987, 2009.

31. Carbone M, Yang H, Pass HI, Krausz T, Testa JR and Gaudino G: BAP1 and cancer. Nat Rev Cancer 13: 153-159, 2013.

32. Harbour JW, Onken MD, Roberson ED, Duan S, Cao L, Worley LA, Council ML, Matatall KA, Helms C and Bowcock AM: Frequent mutation of BAP1 in metastasizing uveal melanomas. Science 330: 1410-1413, 2010.

33. Singh AD, Rennie IG, Seregard S, Giblin M and McKenzie J: Sunlight exposure and pathogenesis of uveal melanoma. Surv Ophthalmol 49: 419-428, 2004.

34. Schmidt-Pokrzywniak A, Jöckel KH, Bornfeld N, Sauerwein W and Stang A: Positive interaction between light iris color and ultraviolet radiation in relation to the risk of uveal melanoma. A case-control study. Ophthalmology 116: 340-348, 2009.

35. Shah CP, Weis E, Lajous M, Shields JA and Shields CL: Intermittent and chronic ultraviolet light exposure and uveal melanoma: A meta-analysis. Ophthalmology 112: 1599-1607, 2005.

36. Fernandes BF, Marshall JC and Burnier MN Jr: Blue light exposure and uveal melanoma. Ophthalmology 113: 1062.e1; author reply 1062, 2006

37. Ge YR, Tian N, Lu Y, Wu Y, Hu QR and Huang ZP: Occupational cooking and risk of uveal melanoma: A meta-analysis. Asian Pac J Cancer Prev 13: 4927-4930, 2012.

38. Damato EM and Damato BE: Detection and time to treatment of uveal melanoma in the United Kingdom: An evaluation of 2,384 patients. Ophthalmology 119: 1582-1589, 2012.

39. Shields CL, Kaliki S, Shah SU, Luo W, Furuta M and Shields JA Iris melanoma: Features and prognosis in 317 children and adults. J AAPOS 16: 10-16, 2012

40. Demirci H, Shields CL, Shields JA, Eagle RC Jr and Honavar SG: Diffuse iris melanoma: A report of 25 cases. Ophthalmology 109: 1553-1560, 2002.

41. Demirci H, Shields CL, Shields JA, Eagle RC Jr and Honavar S: Ring melanoma of the anterior chamber angle: A report of fourteen cases. Am J Ophthalmol 132: 336-342, 2001.

42. Shields CL, Furuta M, Thangappan A, Nagori S, Mashayekhi A, Lally DR, Kelly CC, Rudich DS, Nagori AV, Wakade OA, et al: Metastasis of uveal melanoma millimeter-by-millimeter in 8033 consecutive eyes. Arch Ophthalmol 127: 989-998, 2009.

43. Shields CL, Manalac J, Das C, Ferguson K and Shields JA: Choroidal melanoma: Clinical features, classification, and top 10 pseudomelanomas. Curr Opin Ophthalmol 25: 177-185, 2014.

44. Henderson E and Margo CE: Iris melanoma. Arch Pathol Lab Med 132: 268-272, 2008

45. Singh AD and Damato B (eds): Iris melanoma. In: Clinical Ophthalmic Oncology: Uveal Tumors. Springer, Berlin, pp137-158, 2014.

46. Shields CL, Manquez ME, Ehya H, Mashayekhi A, Danzig CJ and Shields JA: Fine-Needle aspiration biopsy of iris tumors in 100 consecutive cases: Technique and complications. Ophthalmology 113: 2080-2086, 2006.

47. Bianciotto C, Shields CL, Guzman JM, Romanelli-Gobbi M, Mazzuca D Jr, Green WR and Shields JA: Assessment of anterior segment tumors with ultrasound biomicroscopy versus anterior segment optical coherence tomography in 200 cases. Ophthalmology 118: 1297-1302, 2011. 
48. Amaro A, Gangemi R, Piaggio F, Angelini G, Barisione G, Ferrini S and Pfeffer U: The biology of uveal melanoma. Cancer Metastasis Rev 36: 109-140, 2017.

49. Ossoinig KC: Standardized echography: Basic principles, clinical applications, and results. Int Ophthalmol Clin 19: 127-210, 1979.

50. Shields CL, Kaliki S, Rojanaporn D, Ferenczy SR and Shields JA: Enhanced depth imaging optical coherence tomography of small choroidal melanoma: Comparison with choroidal nevus. Arch Ophthalmol 130: 850-856, 2012.

51. Augsburger JJ, Golden MI and Shields JA: Fluorescein angiography of choroidal malignant melanomas with retinal invasion. Retina 4: 232-241, 1984.

52. Shields CL, Shields JA and De Potter P: Patterns of indocyanine green videoangiography of choroidal tumours. $\mathrm{Br}$ J Ophthalmol 79: 237-245, 1995.

53. Shields JA, Mashayekhi A, RaS and Shields CL: Pseudomelanomas of the posterior uveal tract: The 2006 Taylor R. Smith lecture. Retina 25: 767-771, 2005.

54. Shields CL, Dalvin LA, Ancona-Lezama D, Yu MD, Di Nicola M, Williams BK Jr, Lucio-Alvarez JA, Ang SM, Maloney S, Welch RJ and Shields JA: Choroidal nevus imaging features in 3,806 cases and risk factors for transformation into Melanoma in 2,355 cases: The 2020 Taylor R. Smith and Victor T. Curtin Lecture. Retina 39: 1840-1851, 2019.

55. Accuracy of Diagnosis of Choroidal Melanomas in the Collaborative Ocular Melanoma Study: COMS Report No. 1. Arch Ophthalmol 108: 1268-1273, 1990.

56. Char DH and Miller T: Accuracy of presumed uveal melanoma diagnosis before alternative therapy. Br J Ophthalmol 79: 692-696, 1995

57. Shields JA, Shields CL, Ehya H, Eagle RC Jr and De Potter P: Fine-needle aspiration biopsy of suspected intraocular tumors. Int Ophthalmol Clin 33: 77-82, 1993.

58. Frizziero L, Midena E, Trainiti S, Londei D, Bonaldi L, Bini S and Parrozzani R: Uveal melanoma biopsy: A review. Cancers (Basel) 11: 1075, 2019.

59. Kivelä T, Simpson RE and Grossniklaus HE: Uveal melanoma. In: AJCC Cancer Staging Manual. 8th edition. Springer, New York, NY, 2016.

60. Edge S, Byrd D and Compton C, Fritz AG, Greene F and Trotti A (eds): AJCC Cancer Staging Handbook. In: The AJCC Cancer Staging Manual. Springer-Verlag, New York, NY, 2010.

61. Hicks C, Foss AJ and Hungerford JL: Predictive power of screening tests for metastasis in uveal melanoma. Eye (Lond) 12: 945-948, 1998.

62. Weis E, Salopek TG, McKinnon JG, Larocque MP, Temple-Oberle C, Cheng T, McWhae J, Sloboda R and Shea-Budgell M: Management of uveal melanoma: A consensus-based provincial clinical practice guideline. Curr Oncol 23: e57-e64, 2016.

63. Rietschel P, Panageas KS, Hanlon C, Patel A, Abramson DH and Chapman PB: Variates of survival in metastatic uveal melanoma. J Clin Oncol 23: 8076-8080, 2005.

64. Diener-West M, Reynolds SM, Agugliaro DJ, Caldwell R, Cumming K, Earle JD, Hawkins BS, Hayman JA, Jaiyesimi I, Jampol LM, et al: Development of metastatic disease after enrollment in the COMS trials for treatment of choroidal melanoma: Collaborative Ocular Melanoma Study Group Report No. 26. Arch Ophthalmol 123: 1639-1643, 2005.

65. Kivelä T: Iris melanomas in children. Arch Ophthalmol 119: 925-926, 2001

66. Kaliki S, Shields CL, Mashayekhi A, Ganesh A, Furuta M and Shields JA: Influence of age on prognosis of young patients with uveal melanoma: A matched retrospective cohort study. Eur J Ophthalmol 23: 208-216, 2013.

67. Shields CL, Shields JA, Materin M, Gershenbaum E, Singh AD and Smith A: Iris melanoma: Risk factors for metastasis in 169 consecutive patients. Ophthalmology 108: $172-178,2001$

68. Kujala E, Mäkitie T and Kivelä T: Very long-term prognosis of patients with malignant uveal melanoma. Invest Ophthalmol Vis Sci 44: 4651-4659, 2003.

69. Shields CL, Kaliki S, Furuta M, Mashayekhi A and Shields JA Clinical spectrum and prognosis of uveal melanoma based on age at presentation in 8,033 cases. Retina 32: 1363-1372, 2012 .

70. Zloto O, Pe'er J and Frenkel S: Gender differences in clinical presentation and prognosis of uveal melanoma. Invest Ophthalmol Vis Sci 54: 652-656, 2013.
71. Hawkins BS; Collaborative Ocular Melanoma Study Group: The Collaborative Ocular Melanoma Study (COMS) randomized trial of pre-enucleation radiation of large choroidal melanoma: IV. Ten-year mortality findings and prognostic factors. COMS report number 24. Am J Ophthalmol 138: 936-951, 2004

72. Collaborative Ocular Melanoma Study Group: The COMS randomized trial of iodine 125 brachytherapy for choroidal melanoma: V. Twelve-year mortality rates and prognostic factors: COMS report no. 28. Arch Ophthalmol 124: 1684-1693, 2006.

73. Diener-West M, Hawkins BS, Markowitz JA and Schachat AP A review of mortality from choroidal melanoma: II. A Meta-Analysis of 5-Year mortality rates following enucleation, 1966 through 1988. Arch Ophthalmol 110: 245-250, 1992.

74. Shields CL, Kaliki S, Furuta M, Fulco E, Alarcon C and Shields JA: American Joint Committee on cancer classification of posterior uveal melanoma (tumor size category) predicts prognosis in 7731 patients. Ophthalmology 120: 2066-2071, 2013.

75. Li W, Gragoudas ES and Egan KM: Metastatic melanoma death rates by anatomic site after proton beam irradiation for uveal melanoma. Arch Ophthalmol 118: 1066-1070, 2000.

76. Kaliki S, Shields CL and Shields JA: Uveal melanoma: Estimating prognosis. Indian J Ophthalmol 63: 93-102, 2015.

77. Pach JM, Robertson DM, Taney BS, Martin JA, Campbell RJ and O'Brien PC: Prognostic factors in choroidal and ciliary body melanomas with extrascleral extension. Am J Ophthalmol 101: 325-331, 1986

78. McLean MJ, Foster WD and Zimmerman LE: Prognostic factors in small malignant melanomas of choroid and ciliary body. Arch Ophthalmol 95: 48-58, 1977.

79. Al-Jamal RT, Mäkitie T and Kivelä T: Nucleolar diameter and microvascular factors as independent predictors of mortality from malignant melanoma of the choroid and ciliary body. Invest Ophthalmol Vis Sci 44: 2381-2389, 2003.

80. Prescher G, Bornfeld N, Hirche H, Horsthemke B, Jöckel KH and Becher R: Prognostic implications of monosomy 3 in uveal melanoma. Lancet 347: 1222-1225, 1996.

81. Kilic E, Naus NC, Van Gils W, Klaver CC, van Til ME, Verbiest MM, Stijnen T, Mooy CM, Paridaens D, Beverloo HB, et al: Concurrent loss of chromosome arm 1p and chromosome 3 predicts a decreased disease-free survival in uveal melanoma patients. Invest Ophthalmol Vis Sci 46: 2253-2257, 2005.

82. Scholes AG, Damato BE, Nunn J, Hiscott P, Grierson I and Field JK: Monosomy 3 in uveal melanoma: Correlation with clinical and histologic predictors of survival. Invest Ophthalmol Vis Sci 44: 1008-1011, 2003.

83. Ehlers JP, Worley L, Onken MD and Harbour JW: Integrative genomic analysis of aneuploidy in uveal melanoma. Clin Cancer Res 14: 115-122, 2008

84. Aalto Y, Eriksson L, Seregard S, Larsson O and Knuutila S: Concomitant loss of chromosome 3 and whole arm losses and gains of chromosome 1,6 , or 8 in metastasizing primary uveal melanoma. Invest Ophthalmol Vis Sci 42: 313-317, 2001

85. Onken MD, Worley LA, Ehlers JP and Harbour JW: Gene expression profiling in uveal melanoma reveals two molecular classes and predicts metastatic death. Cancer Res 64: 7205-7209, 2004.

86. Onken MD, Worley LA, Char DH, Augsburger JJ, Correa ZM, Nudleman E, Aaberg TM Jr, Altaweel MM, Bardenstein DS, Finger PT, et al: Collaborative ocular oncology group report number 1: Prospective validation of a multi-gene prognostic assay in uveal melanoma. Ophthalmology 119: 1596-1603, 2012.

87. Harbour JW and Chen R: The DecisionDx-UM gene expression profile test provides risk stratification and individualized patient care in uveal melanoma. PLoS Curr: April 9, 2013 (Epub ahead of print). doi: 10.1371/currents.eogt.af8ba80fc776c8f1 ce $8 f 5 d c 485 d 4 a 618$

88. Field MG and Harbour JW: Recent developments in prognostic and predictive testing in uveal melanoma. Curr Opin Ophthalmol 25: 234-239, 2014

89. Eskelin S, Pyrhönen S, Summanen P, Hahka-Kemppinen M and Kivelä T: Tumor doubling times in metastatic malignant melanoma of the uvea: Tumor progression before and after treatment. Ophthalmology 107: 1443-1449, 2000.

90. Natarajan S: Ocular oncology-a multidisciplinary specialty. Indian J Ophthalmol 63: 91, 2015.

91. Rantala ES, Hernberg M and Kivelä TT: Overall survival after treatment for metastatic uveal melanoma: A systematic review and meta-analysis. Melanoma Res 29: 561-568, 2019. 
92. Brewington BY, Shao YF, Davidorf FH and Cebulla CM: Brachytherapy for patients with uveal melanoma: Historical perspectives and future treatment directions. Clin Ophthalmol 12: 925-934, 2018.

93. Rospond-Kubiak I and Damato B: The surgical approach to the management of anterior uveal melanomas. Eye (Lond) 28 741-747, 2014.

94. Jonas JB, Groh MJ, Rummelt V and Naumann GOH: Rhegmatogenous retinal detachment after block excision of epithelial implantation cysts and tumors of the anterior uvea Ophthalmology 106: 1942-1946, 1999.

95. Nelson F, Stine GH and Danielson RW: Malignant melanoma of iris and ciliary body. Am J Ophthalmol 29: 1310, 1946.

96. Damato B, Kacperek A, Chopra M, Sheen MA, Campbell IR and Errington RD: Proton beam radiotherapy of iris melanoma Int J Radiat Oncol Biol Phys 63: 109-115, 2005.

97. Finger PT: Plaque radiation therapy for malignant melanoma of the iris and ciliary body. Am J Ophthalmol 132: 328-335, 2001

98. Shields CL, Naseripour M, Shields JA, Freire J and Cater J: Custom-designed plaque radiotherapy for nonresectable iris melanoma in 38 patients: Tumor control and ocular complications. Am J Ophthalmol 135: 648-656, 2003.

99. Lloyd JP and Ellis F: Melanoma of iris treated by radiation therapy. Br J Ophthalmol 39: 507-509, 1955

100. Konstantinidis L, Roberts D, Errington RD, Kacperek A and Damato B: Whole anterior segment proton beam radiotherapy for diffuse iris melanoma. Br J Ophthalmol 97: 471-474, 2013.

101. Finger PT, Tomar AS and Chin KJ: Palladium-103 plaque therapy for multifocal iris melanoma: Radiation of the entire anterior segment of the eye. Eur J Ophthalmol 1120672120914235, 2020 (Epub ahead of print).

102. Rundle P, Singh AD and Rennie I: Proton beam therapy for iris melanoma: A review of 15 cases. Eye (Lond) 21: 79-82, 2007.

103. Rahmi A, Mammar H, Thariat J, Angellier G, Herault J, Chauvel P, Kodjikian L, Denis P and Grange JD: Proton beam therapy for presumed and confirmed iris melanomas: A review of 36 cases. Graefes Arch Clin Exp Ophthalmol 252: 1515-1521, 2014.

104. Shields CL, Shah SU, Bianciotto CG, Emrich J, Komarnicky L and Shields JA: Iris melanoma management with iodine-125 plaque radiotherapy in 144 patients: Impact of melanoma-related glaucoma on outcomes. Ophthalmology 120: 55-61, 2013.

105. American Brachytherapy Society-Ophthalmic Oncology Task Force. Electronic address: paulfinger@eyecancer.com; ABS-OOTF Committee: The American Brachytherapy Society consensus guidelines for plaque brachytherapy of uveal melanoma and retinoblastoma. Brachytherapy 13: 1-14, 2014.

106. Dogrusöz M, Jager MJ and Damato B: Uveal melanoma treatment and prognostication. Asia Pac J Ophthalmol (Phila) 6 186-196, 2017.

107. Honavar SG: Is collaborative ocular melanoma study (COMS) still relevant? Indian J Ophthalmol 66: 1385-1387, 2018.

108. Damato B: Legacy of the collaborative ocular melanoma study. Arch Ophthalmol 125: 966-968, 2007.

109. Zimmerman LE, McLean IW and Foster WD: Does enucleation of the eye containing a malignant melanoma prevent or accelerate the dissemination of tumour cells? Br J Ophthalmol 62 420-425, 1978

110. Hawkins BS: Collaborative Ocular Melanoma Study randomized trial of I-125 brachytherapy. Clin Trials 8: 661-673, 2011

111. Finger PT, Chin KJ and Duvall G; Palladium-103 for Choroida Melanoma Study Group: Palladium-103 ophthalmic plaque radiation therapy for choroidal melanoma: 400 treated patients. Ophthalmology 116: 790-6, 796.e1, 2009.

112. Verma V and Mehta MP: Clinical outcomes of proton radiotherapy for uveal melanoma. Clin Oncol (R Coll Radiol) 28 e17-e27, 2016

113. Gragoudas ES: Proton beam irradiation of uveal melanomas: The first 30 years. The weisenfeld lecture. Invest Ophthalmo Vis Sci 47: 4666-4673, 2006.

114. Yang J, Manson DK, Marr BP and Carvajal RD: Treatment of uveal melanoma: Where are we now? Ther Adv Med Oncol 10 1758834018757175,2018

115. Damato B, Kacperek A, Errington D and Heimann H: Proton beam radiotherapy of uveal melanoma. Saudi J Ophthalmol 27: 151-157, 2013

116. Papakostas TD, Lane AM, Morrison M, Gragoudas ES and Kim IK: Long-term outcomes after proton beam irradiation in patients with large choroidal melanomas. JAMA Ophthalmol 135: 1191-1196, 2017.
117. Dunavoelgyi R, Dieckmann K, Gleiss A, Sacu S, Kircher K, Georgopoulos M, Georg D, Zehetmayer M and Poetter R: Local tumor control, visual acuity, and survival after hypofractionated stereotactic photon radiotherapy of choroidal melanoma in 212 patients treated between 1997 and 2007. Int J Radiat Oncol Biol Phys 81: 199-205, 2011

118. Gragoudas ES, Li W, Lane AM, Munzenrider J and Egan KM: Risk factors for radiation maculopathy and papillopathy after intraocular irradiation. Ophthalmology 106: 1571-1578, 1999.

119. Shields JA and Shields CL: Management of posterior uveal melanoma: Past, present, and Future: The 2014 Charles L. schepens lecture. Ophthalmology 122: 414-428, 2015.

120. Damato B and Lecuona K: Conservation of eyes with choroidal melanoma by a multimodality approach to treatment: An audit of 1632 patients. Ophthalmology 111: 977-983, 2004.

121. Shields JA, Shields CL, Shah P and Sivalingam V: Partial lamellar sclerouvectomy for ciliary body and choroidal tumors. Ophthalmology 98: 971-983, 1991

122. Peyman GA and Gremillion CM: Eye wall resection in the management of uveal neoplasms. Jpn J Ophthalmol 33: 458-471, 1989.

123. Damato BE, Paul J and Foulds WS: Predictive factors of visual outcome after local resection of choroidal melanoma. Br J Ophthalmol 77: 616-623, 1993.

124. Foulds WS, Damato BE and Burton RL: Local resection versus enucleation in the management of choroidal melanoma. Eye (Lond) 1 (Pt 6): 676-679, 1987.

125. Damato BE, Paul J and Foulds WS: Risk factors for residual and recurrent uveal melanoma after trans-scleral local resection. Br J Ophthalmol 80: 102-108, 1996.

126. Caminal JM, Padrón-Pérez N, Arias L, Masuet-Aumatell C, Gutiérrez C, Piulats JM, Pera J, Català J, Rubio MJ and Arruga J: Transscleral resection without hypotensive anaesthesia vs iodine-125 plaque brachytherapy in the treatment of choroidal melanoma. Eye (Lond) 30: 833-842, 2016.

127. Konstantinidis L, Groenewald C, Coupland SE and Damato B Long-term outcome of primary endoresection of choroidal melanoma. Br J Ophthalmol 98: 82-85, 2014.

128. Biewald E, Lautner H, Gök M, Horstmann GA, Sauerwein W, Flühs D and Bornfeld N: Endoresection of large uveal melanomas: Clinical results in a consecutive series of 200 cases. Br J Ophthalmol 101: 204-208, 2017.

129. Süsskind D, Dürr C, Paulsen F, Kaulich T and Bartz-Schmidt KU: Endoresection with adjuvant ruthenium brachytherapy for selected uveal melanoma patients-the Tuebingen experience. Acta Ophthalmol 95: e727-e733, 2017.

130. Mashayekhi A, Shields CL, Rishi P, Atalay HT, Pellegrini M, McLaughlin JP, Patrick KA, Morton SJ, Remmer MH, Parendo A, et al: Primary transpupillary thermotherapy for choroidal melanoma in 391 cases: Importance of risk factors in tumor control. Ophthalmology 122: 600-609, 2015

131. Shields CL, Shields JA, Perez N, Singh AD and Cater J: Primary transpupillary thermotherapy for small choroidal melanoma in 256 consecutive cases: Outcomes and limitations. Ophthalmology 109: 225-234, 2002.

132. Harbour JW, Meredith TA, Thompson PA and Gordon ME: Transpupillary thermotherapy versus plaque radiotherapy for suspected choroidal melanomas. Ophthalmology 110: 2207-2214; discussion 2215, 2003

133. Yarovoy AA, Magaramov DA and Bulgakova ES: The comparison of ruthenium brachytherapy and simultaneous transpupillary thermotherapy of choroidal melanoma with brachytherapy alone. Brachytherapy 11: 224-229, 2012.

134. Marinkovic M, Horeweg N, Fiocco M, Peters FP, Sommers LW, Laman MS, Bleeker JC, Ketelaars M, Luyten GP and Creutzberg CL: Ruthenium-106 brachytherapy for choroidal melanoma without transpupillary thermotherapy: Similar efficacy with improved visual outcome. Eur J Cancer 68: 106-113, 2016.

135. Desjardins L, Lumbroso-Le Rouic L, Levy-Gabriel C, Dendale R, Delacroix S, Nauraye C, Estève M, Plancher C and Asselain B: Combined proton beam radiotherapy and transpupillary thermotherapy for large uveal melanomas: A randomized study of 151 patients. Ophthalmic Res 38: 255-260, 2006.

136. Bellerive C, Aziz HA, Bena J, Wilkinson A, Suh JH, Plesec T and Singh AD: Local failure after episcleral brachytherapy for posterior uveal melanoma: Patterns, risk factors, and management. Am J Ophthalmol 177: 9-16, 2017.

137. Cerman E and Çekiç O: Clinical use of photodynamic therapy in ocular tumors. Surv Ophthalmol 60: 557-574, 2015. 
138. Turkoglu EB, Pointdujour-Lim R, Mashayekhi A and Shields CL: Photodynamic therapy as primary treatment for small choroidal melanoma. Retina 39: 1319-1325, 2019

139. Liggett PE, Lavaque AJ, Chaudhry NA, Jablon EP and Quiroz-Mercado H: Preliminary results of combined simultaneous transpupillary thermotherapy and ICG-based photodynamic therapy for choroidal melanoma. Ophthalmic Surg Lasers Imaging 36: 463-470, 2005.

140. Rose AM, Cowen S, Jayasena CN, Verity DH and Rose GE: Presentation, treatment, and prognosis of secondary melanoma within the orbit. Front Oncol 7: 125, 2017.

141. Finger PT and Chin KJ: Antivascular endothelial growth factor bevacizumab for radiation optic neuropathy: Secondary to plaque radiotherapy. Int J Radiat Oncol Biol Phys 82: 789-798, 2012

142. Nagendran ST and Finger PT: Anti-VEGF intravitreal bevacizumab for radiation-associated neovascular glaucoma. Ophthalmic Surg Lasers Imaging Retin 46: 201-207, 2015.

143. Fallico M, Chronopoulos A, Schutz JS and Reibaldi M: Treatment of radiation maculopathy and radiation-induced macular edema: A systematic review. Surv Ophthalmol: Sep 10, 2020 (Epub ahead of print). doi: 10.1016/j.survophthal.2020.08.007.

144. Fallico M, Reibaldi M, Avitabile T, Longo A, Bonfiglio V, Chronopoulos A, Caltabiano R, Spatola C and Russo A: Intravitreal aflibercept for the treatment of radiation-induced macular edema after ruthenium 106 plaque radiotherapy for choroidal melanoma. Graefes Arch Clin Exp Ophthalmol 257: 1547-1554, 2019.

145. Gomez D, Wetherill C, Cheong J, Jones L, Marshall E, Damato B, Coupland SE, Ghaneh P, Poston GJ, Malik HZ and Fenwick SW: The Liverpool uveal melanoma liver metastases pathway: Outcome following liver resection. J Surg Oncol 109: 542-547, 2014

146. Davanzo JM, Binkley EM, Bena JF and Singh AD: Risk-stratified systemic surveillance in uveal melanoma. Br J Ophthalmol 103: $1868-1871,2019$.

147. Carvajal RD, Schwartz GK, Tezel T, Marr B, Francis JH and Nathan PD: Metastatic disease from uveal melanoma: Treatment options and future prospects. Br J Ophthalmol 101: 38-44, 2017

148. Ralli M, Botticelli A, Visconti IC, Angeletti D, Fiore M, Marchetti P, Lambiase A, de Vincentiis M and Greco A: Immunotherapy in the treatment of metastatic melanoma: Current knowledge and future directions. J Immunol Res 2020 : 9235638, 2020

149. Basile MS, Mazzon E, Russo A, Mammana S, Longo A, Bonfiglio V, Fallico M, Caltabiano R, Fagone P, Nicoletti F, et al: Differential modulation and prognostic values of immune-escape genes in uveal melanoma. PLoS One 14: e0210276, 2019

150. Basile MS, Mazzon E, Fagone P, Longo A, Russo A, Fallico M, Bonfiglio V, Nicoletti F, Avitabile T and Reibaldi M: Immunobiology of uveal melanoma: State of the art and therapeutic targets. Front Oncol 9: 1145, 2019.

151. Schadendorf D, Ascierto PA, Haanen JBAG, Espinosa E, Demidov LV, Garbe C, Lorigan P, Gogas H, Hoeller C, Guren TK, et al: Efficacy and safety of nivolumab (NIVO) in patients with advanced melanoma (MEL) and poor prognostic factors who progressed on or after ipilimumab (IPI): Results from a phase II study (CheckMate 172). J Clin Oncol 35 (Suppl 15): S9524, 2017.

152. Najjar YG, Navrazhina K, Ding F, Bhatia R, Tsai K, Abbate K, Durden B, Eroglu Z, Bhatia S, Park S, et al: Ipilimumab plus nivolumab for patients with metastatic uveal melanoma: A multicenter, retrospective study. J Immunother Cancer 8: e000331, 2020

153. Cruz F, Rubin BP, Wilson D, Town A, Schroeder A, Haley A, Bainbridge T, Heinrich MC and Corless CL: Absence of BRAF and NRAS mutations in uveal melanoma. Cancer Res 63 5761-5766, 2003.

154. Carvajal RD, Sosman JA, Quevedo JF, Milhem MM, Joshua AM, Kudchadkar RR, Linette GP, Gajewski TF, Lutzky J, Lawson DH, et al: Effect of selumetinib vs chemotherapy on progression-free survival in uveal melanoma: A randomized clinical trial. JAMA 311: 2397-2405, 2014.

155. Carvajal RD, Piperno-Neumann S, Kapiteijn E, Chapman PB, Frank S, Joshua AM, Piulats JM, Wolter P, Cocquyt V, Chmielowski B, et al: Selumetinib in combination with dacarbazine in patients with metastatic uveal melanoma: A phase III, multicenter, randomized trial (SUMIT). J Clin Oncol 36: 1232-1239, 2018.
156. Falchook GS, Lewis KD, Infante JR, Gordon MS, Vogelzang NJ DeMarini DJ, Sun P, Moy C, Szabo SA, Roadcap LT, et al: Activity of the oral MEK inhibitor trametinib in patients with advanced melanoma: A phase 1 dose-escalation trial. Lancet Oncol 13: 782-789, 2012.

157. Shoushtari AN, Kudchadkar RR, Panageas K, Murthy RK, Jung M, Shah R, O'Donnell B, Khawaja TT, Shames Y, Prempeh-Keteku NA, et al: A randomized phase 2 study of trametinib with or without GSK2141795 in patients with advanced uveal melanoma. J Clin Oncol 34 (Suppl 15): S9511, 2016.

158. Piperno-Neumann S, Kapiteijn E, Larkin JM, Carvajal RD, Luke JJ, Roozen HS, Zoubir M, Yang L, Choudhury S, Yerramilli-Rao P, et al: Phase I dose-escalation study of the protein kinase C (PKC) inhibitor AEB071 in patients with metastatic uveal melanoma. J Clin Oncol 32 (Suppl 15): 9030, 2014.

159. Mahipal A, Tijani L, Chan K, Laudadio M, Mastrangelo MJ and Sato T: A pilot study of sunitinib malate in patients with metastatic uveal melanoma. Melanoma Res 22: 440-446, 2012.

160. Valsecchi ME, Orloff M, Sato R, Chervoneva I, Shields CL, Shields JA, Mastrangelo MJ and Sato T: Adjuvant sunitinib in high-risk patients with uveal melanoma: Comparison with institutional controls. Ophthalmology 125: 210-217, 2018.

161. Luke JJ, Olson DJ, Allred JB, Strand CA, Bao R, Zha Y, Carll T, Labadie BW, Bastos BR, Butler MO, et al: Randomized Phase II trial and tumor mutational spectrum analysis from cabozantinib versus chemotherapy in metastatic uveal melanoma (Alliance A091201). Clin Cancer Res 26: 804-811, 2020.

162. Scheulen ME, Kaempgen E, Keilholz U, Heinzerling L, Ochsenreither S, Abendroth A, Hilger RA, Grubert M, Wetter A, Guberina N, et al: STREAM: A randomized discontinuation, blinded, placebo-controlled phase II study of sorafenib (S) treatment of chemonaïve patients (pts) with metastatic uveal melanoma (MUM). J Clin Oncol 35: 9511-9511, 2017.

163. Khoja L, Atenafu EG, Suciu S, Leyvraz S, Sato T, Marshall E, Keilholz U, Zimmer L, Patel SP, Piperno-Neumann S, et al: Meta-analysis in metastatic uveal melanoma to determine progression free and overall survival benchmarks: An international rare cancers initiative (IRCI) ocular melanoma study. Ann Oncol 30: 1370-1380, 2019.

164. Rowcroft A, Loveday BPT, Thomson BNJ, Banting S and Knowles B: Systematic review of liver directed therapy for uveal melanoma hepatic metastases. HPB (Oxford) 22: 497-505, 2020.

165. Leyvraz S, Piperno-Neumann S, Suciu S, Baurain JF, Zdzienicki M, Testori A, Marshall E, Scheulen M, Jouary T, Negrier S, et al: Hepatic intra-arterial versus intravenous fotemustine in patients with liver metastases from uveal melanoma (EORTC 18021): A multicentric randomized trial. Ann Oncol 25: 742-746, 2014

166. Vogl TJ, Koch SA, Lotz G, Gebauer B, Willinek W, Engelke C, Brüning R, Zeile M, Wacker F, Vogel A, et al: Percutaneous isolated hepatic perfusion as a treatment for isolated hepatic metastases of uveal melanoma: Patient outcome and safety in a multi-centre study. Cardiovasc Intervent Radiol 40: 864-872, 2017.

167. Gonsalves CF, Eschelman DJ, Adamo RD, Anne PR, Orloff MM, Terai M, Hage AN, Yi M, Chervoneva I and Sato T: A prospective Phase II trial of radioembolization for treatment of uveal melanoma hepatic metastasis. Radiology 293: 223-231, 2019.

168. Sharma A, Stei MM, Fröhlich H, Holz FG, Loeffler KU and Herwig-Carl MC: Genetic and epigenetic insights into uveal melanoma. Clin Genet 93: 952-961, 2018

169. Lobo J, Pinto C, Freitas M, Pinheiro M, Vizcaino R, Oliva E, Teixeira MR, Jerónimo $\mathrm{C}$ and Bartosch C: Ovarian metastasis from uveal melanoma with MLH1/PMS2 protein loss in a patient with germline MLH1 mutated Lynch syndrome: Consequence or coincidence? Virchows Arch 470: 347-352, 2017.

170. Rai K, Pilarski R, Cebulla CM and Abdel-Rahman MH: Comprehensive review of BAP1 tumor predisposition syndrome with report of two new cases. Clin Genet 89: 285-294, 2016.

171. Larribère L and Utikal J: Update on GNA alterations in cancer: Implications for uveal melanoma treatment. Cancers (Basel) 12: $1524,2020$.

172. Leonardi GC, Falzone L, Salemi R, Zanghì A, Spandidos DA, Mccubrey JA, Candido S and Libra M: Cutaneous melanoma: From pathogenesis to therapy (Review). Int J Oncol 52: 1071-1080, 2018. 
173. Van Raamsdonk CD, Griewank KG, Crosby MB, Garrido MC, Vemula S, Wiesner T, Obenauf AC, Wackernagel W, Green G, Bouvier N, et al: Mutations in GNA11 in Uveal Melanoma. N Engl J Med 363: 2191-2199, 2010.

174. Onken MD, Worley LA, Long MD, Duan S, Council ML, Bowcock AM and Harbour JW: Oncogenic mutations in GNAQ occur early in uveal melanoma. Invest Ophthalmol Vis Sci 49: 5230-5234, 2008

175. Landreville S, Agapova OA, Matatall KA, Kneass ZT, Onken MD, Lee RS, Bowcock AM and Harbour JW: Histone deacetylase inhibitors induce growth arrest and differentiation in uveal melanoma. Clin Cancer Res 18: 408-416, 2012.

176. Abdel-Rahman MH, Pilarski R, Cebulla CM, Massengill JB, Christopher BN, Boru G, Hovland P and Davidorf FH: Germline BAP1 mutation predisposes to uveal melanoma, lung adenocarcinoma, meningioma, and other cancers. J Med Genet 48: 856-859, 2011

177. Levinzon L, Madigan M, Nguyen V, Hasic E, Conway M and Cherepanoff S: Tumour expression of histone deacetylases in uveal melanoma. Ocul Oncol Pathol 5: 153-161, 2019.

178. Fabbri $\mathrm{M}$ and Calin GA: Epigenetics and miRNAs in human cancer. Adv Genet 70: 87-99, 2010.

179. Cedar $\mathrm{H}$ and Bergman Y: Linking DNA methylation and histone modification: Patterns and paradigms. Nat Rev Genet 10: 295-304, 2009.

180. Zhang W and Xu J: DNA methyltransferases and their roles in tumorigenesis. Biomark Res 5: 1, 2017.

181. Li S, Zhang J, Huang S and He X: Genome-wide analysis reveals that exon methylation facilitates its selective usage in the human transcriptome. Brief Bioinform 19: 754-764, 2018.

182. Jones PA and Laird PW: Cancer epigenetics comes of age. Nat Genet 21: 163-167, 1999.

183. Falzone L, Salemi R, Travali S, Scalisi A, McCubrey JA Candido S and Libra M: MMP-9 overexpression is associated with intragenic hypermethylation of MMP9 gene in melanoma. Aging (Albany NY) 8: 933-944, 2016.

184. Zhao Y, Sun H and Wang H: Long noncoding RNAs in DNA methylation: New players stepping into the old game. Cell Biosci 6: 45, 2016.

185. Shayevitch R, Askayo D, Keydar I and Ast G: The importance of DNA methylation of exons on alternative splicing. RNA 24 1351-1362, 2018.

186. Ehrlich M and Lacey M: DNA methylation and differentiation: Silencing, upregulation and modulation of gene expression. Epigenomics 5: 553-568, 2013.

187. Field MG, Durante MA, Decatur CL, Tarlan B, Oelschlager KM Stone JF, Kuznetsov J, Bowcock AM, Kurtenbach S and Harbour JW: Epigenetic reprogramming and aberrant expression of PRAME are associated with increased metastatic risk in Class 1 and 2 uveal melanomas. Oncotarget 7: 59209-59219, 2016

188. Venza M, Visalli M, Catalano T, Beninati C, Teti D and Venza I: DSS1 promoter hypomethylation and overexpression predict poor prognosis in melanoma and squamous cell carcinoma patients. Hum Pathol 60: 137-146, 2017.

189. Merhavi E, Cohen Y, Avraham BC, Frenkel S, Chowers I, Pe'er J and Goldenberg-Cohen N: Promoter methylation status of multiple genes in uveal melanoma. Invest Ophthalmol Vis Sci 48: 4403-4406, 2007.

190. Moulin AP, Clément G, Bosman FT, Zografos L and Benhattar J: Methylation of $\mathrm{CpG}$ island promoters in uveal melanoma Br J Ophthalmol 92: 281-285, 2008 .

191. Maat W, Van Der Velden PA, Out-Luiting C, Plug M, Dirks-Mulder A, Jager MJ and Gruis NA: Epigenetic inactivation of RASSF1a in uveal melanoma. Invest Ophthalmol Vis Sci 48: 486-490, 2007.

192. Maat W, Beiboer SH, Jager MJ, Luyten GP, Gruis NA and Van Der Velden PA: Epigenetic regulation identifies RASEF as a tumor-suppressor gene in uveal melanoma. Invest Ophthalmol Vis Sci 49: 1291-1298, 2008.

193. Van der Velden PA, Zuidervaart W, Hurks MH, Pavey S, Ksander BR, Krijgsman E, Frants RR, Tensen CP, Willemze R, Jager MJ and Gruis NA: Expression profiling reveals that methylation of TIMP3 is involved in uveal melanoma development. Int J Cancer 106: 472-479, 2003.

194. Neumann LC, Weinhäusel A, Thomas S, Horsthemke B, Lohmann DR and Zeschnigk M: EFS shows biallelic methylation in uveal melanoma with poor prognosis as well as tissue-specific methylation. BMC Cancer 11: 380, 2011.
195. Venza M, Visalli M, Catalano T, Fortunato C, Oteri R, Teti D and Venza I: Impact of DNA methyltransferases on the epigenetic regulation of tumor necrosis factor-related apoptosis-inducing ligand (TRAIL) receptor expression in malignant melanoma. Biochem Biophys Res Commun 441: 743-750, 2013.

196. Field MG, Kuznetsov JN, Bussies PL, Cai LZ, Alawa KA, Decatur CL, Kurtenbach S and Harbour JW: BAP1 loss is associated with DNA methylomic repatterning in highly aggressive class 2 uveal melanomas. Clin Cancer Res 25: 5663-5673, 2019.

197. Falzone L, Romano GL, Salemi R, Bucolo C, Tomasello B, Lupo G, Anfuso CD, Spandidos DA, Libra M and Candido S: Prognostic significance of deregulated microRNAs in uveal melanomas. Mol Med Rep 19: 2599-2610, 2019.

198. Beyer S, Fleming J, Meng W, Singh R, Haque SJ and Chakravarti A: The Role of miRNAs in angiogenesis, invasion and metabolism and their therapeutic implications in gliomas. Cancers (Basel) 9: 85, 2017.

199. Napoli S, Scuderi C, Gattuso G, Bella VD, Candido S, Basile MS, Libra M and Falzone L: Functional roles of matrix metalloproteinases and their inhibitors in melanoma. Cells 9: 1151,2020

200. Filetti V, Falzone L, Rapisarda V, Caltabiano R, Eleonora Graziano AC, Ledda C and Loreto C: Modulation of microRNA expression levels after naturally occurring asbestiform fibers exposure as a diagnostic biomarker of mesothelial neoplastic transformation. Ecotoxicol Environ Saf 198: 110640, 2020.

201. Falzone L, Grimaldi M, Celentano E, Augustin LSA and Libra M: Identification of modulated MicroRNAs associated with breast cancer, diet, and physical activity. Cancers (Basel) 12: 2555, 2020.

202. Polo A, Crispo A, Cerino P, Falzone L, Candido S, Giudice A, De Petro G, Ciliberto G, Montella M, Budillon A and Costantini S: Environment and bladder cancer: Molecular analysis by interaction networks. Oncotarget 8: 65240-65252, 2017

203. Crimi S, Falzone L, Gattuso G, Grillo CM, Candido S, Bianchi A and Libra M: Droplet Digital PCR analysis of liquid biopsy samples unveils the diagnostic role of hsa-miR-133a-3p and hsa-miR-375-3p in oral cancer. Biology (Basel) 9: 379, 2020.

204. Venza M, Dell'Aversana C, Visalli M, Altucci L, Teti D and Venza I: Identification of microRNA expression patterns in cutaneous and uveal melanoma cell lines. Tumori 100: e4-e7, 2014.

205. Radhakrishnan A, Badhrinarayanan N, Biswas J and Krishnakumar S: Analysis of chromosomal aberration $(1,3$ and 8 ) and association of microRNAs in uveal melanoma. Mol Vis 15: 2146-2154, 2009

206. Larsen AC, Holst L, Kaczkowski B, Andersen MT, Manfé V, Siersma VD, Kolko M, Kiilgaard JF, Winther O, Prause JU, et al: MicroRNA expression analysis and Multiplex ligation-dependent probe amplification in metastatic and non-metastatic uveal melanoma. Acta Ophthalmol 92: 541-549, 2014.

207. Worley LA, Long MD, Onken MD and Harbour JW: Micro-RNAs associated with metastasis in uveal melanoma identified by multiplexed microarray profiling. Melanoma Res 18: 184-190, 2008

208. Chen X, Wang J, Shen H, Lu J, Li C, Hu DN, Dong XD, Yan D and $\mathrm{Tu}$ L: Epigenetics, microRNAs, and carcinogenesis: Functional role of microRNA-137 in uveal melanoma. Invest Ophthalmol Vis Sci 52: 1193-1199, 2011

209. Li Y, Huang Q, Shi X, Jin X, Shen L, Xu X and Wei W: MicroRNA 145 may play an important role in uveal melanoma cell growth by potentially targeting insulin receptor substrate-1. Chin Med J (Engl) 127: 1410-1416, 2014.

210. Eedunuri VK, Rajapakshe K, Fiskus W, Geng C, Chew SA, Foley C, Shah SS, Shou J, Mohamed JS, Coarfa C, et al: miR-137 targets p160 steroid receptor coactivators SRC1, SRC2, and SRC3 and inhibits cell proliferation. Mol Endocrinol 29: 1170-1183, 2015

211. Venza M, Visalli M, Beninati C, Benfatto S, Teti D and Venza I: miR-92a-3p and MYCBP2 are involved in MS-275-induced and c-myc-mediated TRAIL-sensitivity in melanoma cells. Int Immunopharmacol 40: 235-243, 2016.

212. Sun L, Bian G, Meng Z, Dang G, Shi D and Mi S: MiR-144 inhibits uveal melanoma cell proliferation and invasion by regulating c-Met expression. PLoS One 10: e0124428, 2015.

213. Zhang L, He X, Li F, Pan H, Huang X, Wen X, Zhang H, Li B, Ge S, Xu X, et al: The miR-181 family promotes cell cycle by targeting CTDSPL, a phosphatase-like tumor suppressor in uveal melanoma. J Exp Clin Cancer Res 37: 15, 2018. 
214. Wang Y, Luo Y, Guan W and Zhao H: Role of mir-23a/zeb1 negative feedback loop in regulating epithelial-mesenchymal transition and tumorigenicity of intraocular tumors. Oncol Lett 16: 2462-2470, 2018.

215. Wang YC, Yang X, Wei WB and Xu XL: Role of microRNA-21 in uveal melanoma cell invasion and metastasis by regulating p53 and its downstream protein. Int J Ophthalmol 11: 1258-1268, 2018.

216. Li J, Liu X, Li C and Wang W: miR-224-5p inhibits proliferation, migration, and invasion by targeting PIK3R3/AKT3 in uveal melanoma. J Cell Biochem 120: 12412-12421, 2019.

217. Sun L, Wang Q, Gao X, Shi D, Mi S and Han Q: MicroRNA-454 functions as an oncogene by regulating PTEN in uveal melanoma. FEBS Lett 589: 2791-2796, 2015.

218. Ling JW, Lu PR, Zhang YB, Jiang S and Zhang ZC: miR-367 promotes uveal melanoma cell proliferation and migration by regulating PTEN. Genet Mol Res 16: 2017.

219. Peng J, Liu H and Liu C: MiR-155 promotes uveal melanoma cell proliferation and invasion by regulating NDFIP1 expression. Technol Cancer Res Treat 16: 1160-1167, 2017.

220. Wang X, Hu Y, Cui J, Zhou Y and Chen L: Coordinated targeting of MMP-2/MMP-9 by miR-296-3p/FOXCUT exerts tumor-suppressing effects in choroidal malignant melanoma. Mol Cell Biochem 445: 25-33, 2018.

221. Zhou J, Jiang J, Wang S and Xia X: Oncogenic role of microRNA-20a in human uveal melanoma. Mol Med Rep 14: 1560-1566, 2016.

222. Yang $C$ and Wei W: The miRNA expression profile of the uveal melanoma. Sci China Life Sci 54: 351-358, 2011.

223. Achberger S, Aldrich W, Tubbs R, Crabb JW, Singh AD and Triozzi PL: Circulating immune cell and microRNA in patients with uveal melanoma developing metastatic disease. Mol Immunol 58: 182-186, 2014.
224. Venza I, Visalli M, Beninati C, Benfatto S, Teti D and Venza M: IL-10R $\alpha$ expression is post-transcriptionally regulated by MIR-15a, MIR-185, and MIR-211 in melanoma. BMC Med Genomics 8: 81, 2015

225. Sun Q, Cong R, Yan H, Gu H, Zeng Y, Liu N, Chen J and Wang B: Genistein inhibits growth of human uveal melanoma cells and affects microRNA-27a and target gene expression. Oncol Rep 22: 563-567, 2009.

226. Tuaeva NO, Falzone L, Porozov YB, Nosyrev AE, Trukhan VM, Kovatsi L, Spandidos DA, Drakoulis N, Kalogeraki A, Mamoulakis C, et al: Translational Application of Circulating DNA in Oncology: Review of the Last Decades Achievements. Cells 8: 1251, 2019.

227. Falzone L, Musso N, Gattuso G, Bongiorno D, Palermo CI, Scalia G, Libra M and Stefani S: Sensitivity assessment of droplet digital PCR for SARS-CoV-2 detection. Int J Mol Med 46: 957-964, 2020.

228. Falzone L, Gattuso G, Lombardo C, Lupo G, Grillo CM, Spandidos DA, Libra M and Salmeri M: Droplet digital PCR for the detection and monitoring of Legionella pneumophila. Int J Mol Med 46: 1777-1782, 2020.

229. Salemi R, Falzone L, Madonna G, Polesel J, Cinà D, Mallardo D, Ascierto PA, Libra M and Candido S: MMP-9 as a candidate marker of response to BRAF inhibitors in melanoma patients with $B R A F^{\mathrm{V} 600 \mathrm{E}}$ mutation detected in circulating-free DNA. Front Pharmacol 9: 856, 2018.

(1)(9) This work is licensed under a Creative Commons International (CC BY-NC-ND 4.0) License. 